\title{
Article \\ Numerical Investigation on Hydrodynamic Performance of a Portable AUV
}

\author{
Lin Hong ${ }^{\mathbb{C}}$, Renjie Fang, Xiaotian Cai and Xin Wang *(i) \\ Harbin Institute of Technology, Shenzhen 518055, China; 20B953023@stu.hit.edu.cn (L.H.); \\ 18B353006@stu.hit.edu.cn (R.F.); cxt1084610290@163.com (X.C.) \\ * Correspondence: wangxinsz@hit.edu.cn
}

Citation: Hong, L.; Fang, R.; Cai, X.; Wang, X. Numerical Investigation on Hydrodynamic Performance of a Portable AUV. J. Mar. Sci. Eng. 2021, 9, 812. https://doi.org/10.3390/ jmse 9080812

Academic Editor: Md Jahir Rizvi

Received: 17 June 2021

Accepted: 19 July 2021

Published: 27 July 2021

Publisher's Note: MDPI stays neutral with regard to jurisdictional claims in published maps and institutional affiliations.

Copyright: (c) 2021 by the authors. Licensee MDPI, Basel, Switzerland. This article is an open access article distributed under the terms and conditions of the Creative Commons Attribution (CC BY) license (https:/ / creativecommons.org/licenses/by/ $4.0 /)$.

\begin{abstract}
This paper conducts a numerical investigation on the hydrodynamic performance of a portable autonomous underwater vehicle (AUV). The portable AUV is designed to cruise and perform some tasks autonomously in the underwater world. However, its dynamic performance is strongly affected by hydrodynamic effects. Therefore, it is crucial to investigate the hydrodynamic performance of the portable AUV for its accurate dynamic modeling and control. In this work, based on the designed portable AUV, a comprehensive hydrodynamic performance investigation was conducted by adopting the computational fluid dynamics (CFD) method. Firstly, the mechanical structure of the portable AUV was briefly introduced, and the dynamic model of the AUV, including the hydrodynamic term, was established. Then, the unknown hydrodynamic coefficients in the dynamic model were estimated through the towing experiment and the plane-motion-mechanism (PMM) experiment simulation. In addition, considering that the portable AUV was affected by wave forces when cruising near the water surface, the influence of surface waves on the hydrodynamic performance of the AUV under different wave conditions and submerged depths was analyzed. Finally, the effectiveness of our method was verified by experiments on the standard models, and a physical experiment platform was built in this work to facilitate hydrodynamic performance investigations of some portable small-size AUVs.
\end{abstract}

Keywords: autonomous underwater vehicle (AUV); numerical investigation; hydrodynamic performance; computational fluid dynamics (CFD)

\section{Introduction}

More than 70\% of the earth's surface is covered by water in the form of oceans, lakes, and rivers [1]. The underwater world is filled with a large number of valuable resources and precious species. However, it is challenging to explore and inspect them due to the inaccessibility, corrosiveness, intense pressure, and optical opacity of the underwater world [2]. In recent decades, with the development of marine technology, many scholars and research institutions have focused on the research of underwater vehicles, which has made significant contributions to the development of various AUVs [3]. The existing AUVs are mainly divided into open-frame and torpedo-shaped. The most commonly used is torpedoshaped AUVs, for they have symmetrical streamlined bodies, which enables them to sail underwater with less resistance and higher efficiency. As an underwater agents, AUVs can perform some underwater tasks such as marine exploration [4], pipe inspection [5], underwater search [6], and rescue [7] through self-sailing and self-execution. However, the maneuverability and controllability of AUVs are strongly influenced by the hydrodynamic forces and moments expressed by a series of hydrodynamic coefficients. Therefore, obtaining the values of these coefficients is very important for the control strategy design of AUVs and ensuring their effective autonomous maneuverability. There have been a lot of investigations on hydrodynamic coefficients estimation of AUVs [8-15], most of them can be divided into experimental evaluation methods, analytical and semi-empirical (ASE) methods, and numerical investigation methods. The early proposed methods for 
investigating AUVs' hydrodynamic performance are experiment-based. These methods are usually implemented in a tank, and the support bars are fixed on some force sensors inside the hull body [16]. A practical and reliable instrument to evaluate the experimental results is the planar motion mechanism (PMM) [17], and there were many reduced or equal-sized AUV models have been made to undertake the PMM experiments for hydrodynamic coefficient estimation. Jagadeesh et al. [13] presented a towing tank-based experimental investigation on forces and moment on AUV hull form in the vertical plane with a 1:2 AUV model of the standard hull form afterbody. It provided guidance experiments on the AUV to study the variation of axial, normal, drag, lift, and pitch moment coefficients with Reynolds number and angle of attack. Nouri et al. [18] developed an apparatus based on planar experiments of a water tunnel to estimate hydrodynamic derivatives due to AUVs velocity and acceleration, and experimental results presented the relationship between regulation parameters and estimated hydrodynamic derivatives. Although PMM tests are very popular among experiment-based methods, the measured data from these tests are not entirely reliable because of experimental difficulties and errors involved, preventing further development of these methods. Another method to estimate the hydrodynamic coefficients of AUVs is the ASE method, which relies on empirical findings and analytic expressions [10]. Kepler et al. [19] proposed an approach to predict the hydrodynamic coefficients of an underwater vehicle by only using its geometric profile. Based on the hydrodynamics and geometric characteristics of submarine vehicles, Cardenas et al. [20] proposed an identification approach that combined an ASE with an extended Kalman filterbased parameter estimator. The ASE estimates are obtained using physical concepts and empirical results collected for typical geometries adopted in underwater vehicles. They provide essential reference values to assess magnitudes and signals for most hydrodynamic coefficients produced by system identification methods.

Recently, many researchers began to apply the CFD methods to the design of more advanced AUVs due to the widespread availability of powerful computers. The numerical estimation method based on empirical formulas [21] or finite element software [14] is the most convenient way to obtain hydrodynamic forces and moments with precisely constructed models. Phillips et al. [22] used the CFD method to predict the dynamic stability derivatives of an AUV. Furthermore, a comparative study of the ASE and the CFD methods for predicting normal force and moment for an AUV is addressed in [10]. The CFD approach allowed for a good prediction of the coefficients over the range of angles of attack considered. Singh et al. [23,24] validated the experimental lift and drag characteristics of a glider from the literature using the CFD approach. This method was then used for the assessment of the steady-state characteristics of a laboratory glider. Gao et al. [25] proposed a time-efficient approach to estimate hydrodynamic coefficients by the CFD method. Instead of a repetitive and time-consuming process, the proposed spatial captive motion could provide necessary information to determine all required coefficients in only one simulation. Safari et al. [26] adopted the CFD tool to numerically simulate the complex unsteady vertical structure of flow due to the manta ray's flapping motion. In [27], hydrodynamic parameters of a mini-AUV were identified via CFD simulations. These parameters were considered to design the three different controllers that were based on the robot manipulators theory. Hydrodynamic coefficients had a dominant effect on the quality of vehicle pre-testing and evaluation. Deng et al. [28] identified an AUV hydrodynamic model using three Kalman filters. Panda et al. [29] provided a review work for investigating hydrodynamic characteristics of AUVs. Nowadays, the CFD method lacks physical-experiment validation. Nevertheless, it holds great promise for the hydrodynamic performance investigation of underwater vehicles.

The existing methods generally consider that the AUV was far away from the water surface and ignored the influence of the surface waves on hydrodynamic performance. However, surface waves have an important impact on the hydrodynamic performance of AUVs cruising near the water surface. Some researchers have used experiment-based or CFD methods to study the influence of water surface on the hydrodynamic performance 
of an AUV presented a towing tank-based experimental study on hydrodynamic forces and moment on an AUV hull near the water surface. Saeidinezhad [15] has numerically investigated the hydrodynamic performance of an AUV model and its interaction with the water surface by the CFD software ANSYS CFX. Shariati et al. [30] studied the effect of appendages on the hydrodynamic performance of the DARPA SUBOFF near the water surface. Tian et al. [31] conducted numerical research on the influence of surface waves on the hydrodynamic performance of an AUV, and the influences of waves are quantitatively analyzed for different wave heights, Reynolds numbers, and submerged depths. Gabl et al. [32] presented a method of quantifying hydrodynamic loads by analyzing the load cell data as forces and moments in relation to the observed motion and rotation of the ROV. Our work focused on the numerical investigation of the hydrodynamic performance of a novel designed AUV (named "Shark-AUV") by adopting the CFD method. Based on the dynamic model of the Shark-AUV, the towing experiment simulation and the PMM experiment simulation were carried out to estimate the unknown hydrodynamic coefficients, and we further systematically analyzed the hydrodynamic performance of the Shark-AUV when cruising near the water surface.

The rest of this paper is organized as follows: the mechanical structure and equations of motion of the Shark-AUV are covered in Section 2. In Section 3, the numerical hydrodynamic performance investigation of the Shark-AUV in various postures, motion states, and wave conditions is conducted. Section 4 presents some experiments for validating the effectiveness of our method, and a physical experiment platform is established for basic hydrodynamic performance investigation of the Shark-AUV. This paper ends with a conclusion in Section 5.

\section{Mechanical Design and Problem Statement}

\subsection{Overall Mechanical Structure}

The Shark-AUV is designed for underwater cruising, inspection, and exploration. It has a symmetrical streamlined body, torpedo-like shape, four propellers, an LED light, an IMU, a depth sensor, and two cameras (the forward-looking camera is used for cruising and obstacle avoidance; the down-looking one is for inspection and exploration of underwater objects on the seafloor), as shown in Figure 1. Its hull is made of stainless steel, sealed with a rubber ring, and the propellers are motor-driven. The AUV has four degrees of freedom: it can complete surge/heave motion through the two horizontal/vertical propellers and realize the yaw/roll motion by changing the speed ratio of two horizontal/vertical propellers. Propulsion force is generated by the rotation of the propeller driven by a motor. The AUV has an overall size of $761.5 \mathrm{~mm} \times 435 \mathrm{~mm} \times 220 \mathrm{~mm}$, a dry weight of approximately $30 \mathrm{~kg}$.
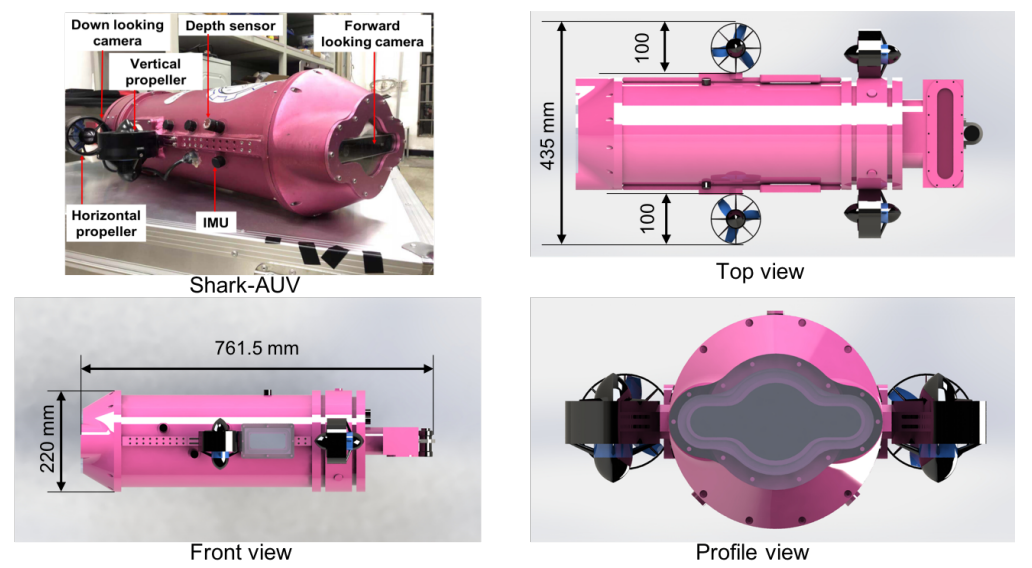

Figure 1. Mechanical structure and configuration of the Shark-AUV. 


\subsection{Equations of Motion}

In this work, two coordinate frames (earth-fixed frame $(E-\xi \eta \zeta)$ and body-fixed frame $(O-x y z))$ are introduced to describe the motion of the Shark-AUV, as shown in Figure 2. The origin of the body-fixed frame is the centre of mass of the AUV, and the center of buoyancy coincides with the center of gravity of the AUV. The positive $O x$ is the forwardcruising direction of the AUV, refer to [33], the equations of motion of the AUV in the body-fixed frame can be expressed as follows:

$$
\begin{array}{ll}
\text { Surge: } & \mathbf{X}=m(\dot{u}-v r+w q) \\
\text { Sway: } & \mathbf{Y}=m(\dot{v}+u r-w p) \\
\text { Heave: } & \mathbf{Z}=m(\dot{w}-u q+v p) \\
\text { Roll: } & \mathbf{K}=I_{x} \dot{p}+\left(I_{z}-I_{y}\right) q r \\
\text { Pitch: } & \mathbf{M}=I_{y} \dot{q}+\left(I_{x}-I_{z}\right) p r \\
\text { Yaw: } & \mathbf{N}=I_{z} \dot{r}+\left(I_{y}-I_{x}\right) p q
\end{array}
$$

where $\mathbf{X}, \mathbf{Y}, \mathbf{Z}, \mathbf{K}, \mathbf{M}$, and $\mathbf{N}$ are resultant forces (gravity, buoyancy, propulsion, hydrodynamic) and moments with respect to $x, y, z$ axis, $m$ is the mass of the AUV, $u, v, w$ represent the velocity of surge, sway, and heave motion, $p, q, r$ represent the angular velocity of roll, pitch, and yaw motion, $I_{x}, I_{y}, I_{z}$ are the inertia momentum of the AUV about the axis $O x$, $O y$, and $O z$, respectively.

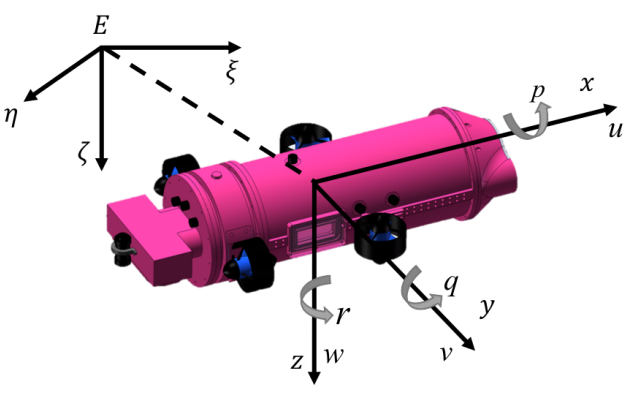

Figure 2. Coordinate frame of the Shark-AUV.

\subsection{Equations of Motion with Unknown Hydrodynamic Coefficients}

For an infinite domain of the underwater environment, the hydrodynamic performance of a given shape AUV is only determined by its motion parameters. The Shark-AUV is designed to cruise at low speed, the influence of the higher derivative of the speed can be ignored. Therefore, the hydrodynamic force $\tau$ can be expressed as

$$
\tau=f(\boldsymbol{\phi}, \dot{\boldsymbol{\phi}}, \omega, \dot{\omega})
$$

where $\boldsymbol{\phi}$ and $\boldsymbol{\omega}$ are the velocity and angular velocity, $\boldsymbol{\phi}=(u, v, w)^{T}, \boldsymbol{\omega}=(p, q, r)^{T}, \dot{\boldsymbol{\phi}}$ and $\dot{\omega}$ are acceleration and angular acceleration of the AUV, respectively. According to the expression of Equation (2), the hydrodynamic force can be divided into viscous hydrodynamic force term and initial hydrodynamic force term. The viscous hydrodynamic force term is determined by the $\phi$ and $\omega$, and initial hydrodynamic force term is determined by the $\dot{\phi}$ and $\dot{\omega}$. With the application of the Taylor series expansion and refer to [8], the hydrodynamic force $\tau_{x}$ along $x$-axis can be expressed as

$$
\begin{aligned}
\tau_{x} & =f_{x}(u, v, w, p, q, r, \dot{u}, \dot{v}, \dot{w}, \dot{p}, \dot{q}, \dot{r})=\tau_{0}+\left(X_{u} \Delta u+X_{v} v+X_{w} w+X_{p} p+X_{q} q+X_{r} r\right) \\
& +\left(X_{\dot{u}} \dot{u}+X_{\dot{v}} \dot{v}+X_{i} \dot{r}+X_{\dot{p}} \dot{p}+X_{\dot{q}} \dot{q}+X_{\dot{r}} \dot{r}\right) \\
& +\frac{1}{2 !}\left(\begin{array}{l}
X_{u u} \Delta u^{2}+X_{w v} v^{2}+X_{p p} p^{2}+X_{q q} q^{2}+X_{r r} r^{2} \\
+2 X_{u v} \Delta u v+2 X_{u w} \Delta u w+2 X_{u p} \Delta u p+2 X_{v r} v s . r \ldots
\end{array}\right)
\end{aligned}
$$


where $X_{u}, X_{v}, X_{w}, X_{p}, X_{q}, X_{r}$ are hydrodynamic coefficients of velocity, $X_{\dot{u}}, X_{\dot{v}}, X_{\dot{w}}, X_{\dot{p}}$, $X_{\dot{q}}, X_{\dot{r}}$ are hydrodynamic coefficients of acceleration, $X_{u u}, X_{p p}, X_{q q}, X_{u v}, X_{u w}, X_{w v} \ldots$ are nonlinear and coupling hydrodynamic coefficients. To improve the computational efficiency of hydrodynamic coefficient investigation, the hydrodynamic forces and moments are normalized by $1 / 2 \rho U^{2} L^{2}$ and $1 / 2 \rho U^{2} L^{3}$, respectively. ( $\rho$ is the fluid density, $U$ is the freestream velocity, $L$ is the length of the AUV hull.) For instance, the coefficient $X_{u}$ after dimensionless normalization is represented as $X_{u}^{\prime}$. Based on the above analysis, equations of motion of the Shark-AUV with unknown hydrodynamic coefficients can be expressed as

$$
\begin{aligned}
& \text { Surge: } m(\dot{u}-v r+w q)=\frac{\rho}{2} L^{4}\left(X_{q q}^{\prime} q^{2}+X_{r r}^{\prime} r^{2}\right) \\
& +\frac{\rho}{2} L^{3}\left(X_{\dot{u}}^{\prime} \dot{u}+X_{v r}^{\prime} v s . r+X_{w q}^{\prime} w q\right)+\frac{\rho}{2} L^{2}\left(X_{u u}^{\prime} u^{2}+X_{v v}^{\prime} v^{2}+X_{w w}^{\prime} w^{2}\right)+T_{x}-(P-B) \sin \theta \\
& \text { Sway: } m(\dot{v}-w p+u r)=\frac{\rho}{2} L^{4}\left(Y_{\dot{r}}^{\prime} \dot{r}+Y_{\dot{p}}^{\prime} \dot{p}+Y_{p q}^{\prime} p q\right) \\
& +\frac{\rho}{2} L^{3}\left[Y_{\dot{v}}^{\prime} \dot{v}+Y_{w p}^{\prime} w p+Y_{r}^{\prime} u r+Y_{v|r|}^{\prime}|v|\left|\left(v^{2}+w^{2}\right)^{\frac{1}{2}}\right||r|\right] \\
& +\frac{\rho}{2} L^{2}\left[Y_{0}^{\prime} u^{2}+Y_{v}^{\prime} u v+Y_{v r}^{\prime} v s \cdot\left|\left(v^{2}+w^{2}\right)^{\frac{1}{2}}\right|+Y_{v w}^{\prime} v s \cdot w\right]+T_{y}-(P-B) \cos \theta \sin \varphi \\
& \text { Heave: } m(\dot{w}-u q+v p)=\frac{\rho}{2} L^{4}\left(Z_{\dot{q}}^{\prime} \dot{q}+Z_{p r}^{\prime} p r\right)+\frac{\rho}{2} L^{3}\left[Z_{\dot{w}}^{\prime} \dot{w}+Z_{v p}^{\prime} v s \cdot p+Z_{q}^{\prime} u q\right] \\
& +\frac{\rho}{2} L^{2}\left[Z_{0}^{\prime} u^{2}+Z_{w}^{\prime} u w+Z_{w w}^{\prime}\left|w\left(v^{2}+w^{2}\right)^{\frac{1}{2}}\right|\right]+T_{z}+(P-B) \cos \theta \cos \varphi \\
& \text { Roll: } I_{x} \dot{p}+\left(I_{z}-I_{y}\right) q r=\frac{\rho}{2} L^{5}\left(K_{\dot{p}}^{\prime} \dot{p}+K_{p q}^{\prime} p q+K_{q r}^{\prime} q r\right) \\
& +\frac{\rho}{2} L^{4}\left(K_{p}^{\prime} u p+K_{v q}^{\prime} v s \cdot q+K_{w p}^{\prime} w p+K_{w r}^{\prime} w r\right)+\frac{\rho}{2} L^{3}\left[K_{0}^{\prime} u^{2}+K_{v w}^{\prime} v s \cdot w\right]-P h \cos \theta \cos \varphi+M_{T x} \\
& \text { Pitch: } I_{y} \dot{q}+\left(I_{x}-I_{z}\right) r p=\frac{\rho}{2} L^{5}\left(M_{\dot{q}}^{\prime} \dot{q}+M_{p r}^{\prime} p r\right)+\frac{\rho}{2} L^{4}\left[M_{\dot{w}}^{\prime} \dot{w}+M_{v p}^{\prime} v s . p+M_{v r}^{\prime} v s . r+M_{q}^{\prime} u q\right] \\
& +\frac{\rho}{2} L^{3}\left[M_{0}^{\prime} u^{2}+M_{w w}^{\prime}\left|w\left(v^{2}+w^{2}\right)^{\frac{1}{2}}\right|+M_{|w|}^{\prime} u|w|\right]-P h \sin \theta+M_{T y} \\
& \text { Yaw: } I_{z} \dot{r}+\left(I_{y}-I_{x}\right) p q=\frac{\rho}{2} L^{5}\left(N_{\dot{r}}^{\prime} \dot{r}+N_{\dot{p}}^{\prime} \dot{p}+N_{p q}^{\prime} p q+N_{q r}^{\prime} q r\right) \\
& +\frac{\rho}{2} L^{4}\left[N_{\dot{v}}^{\prime} \dot{v}+N_{r}^{\prime} u r+N_{w p}^{\prime} w p+N_{v r \mid}^{\prime} \frac{v}{|v|}\left|\left(v^{2}+w^{2}\right)^{\frac{1}{2}}\right| r\right] \\
& +\frac{\rho}{2} L^{3}\left[N_{0}^{\prime} u^{2}+N_{v}^{\prime} u v+N_{v|v|}^{\prime} v s .\left|\left(v^{2}+w^{2}\right)^{\frac{1}{2}}\right|\right]+M_{T z}
\end{aligned}
$$

\subsection{Problem Statement}

As shown in Equation (4), the equations of motion of the Shark-AUV are expressed by many unknown hydrodynamic coefficients. The controllability of the AUV is strongly affected by the hydrodynamic force and moments expressed by these unknown hydrodynamic coefficients. Therefore, this work aims to estimate these unknown hydrodynamic coefficients by the CFD method, so as to investigate the influence of hydrodynamic effects on the dynamic performance of the AUV. In addition, this work also considers that the dynamic performance of the AUV will be affected by wave forces when cruising near the water surface, the hydrodynamic performance of the AUV near the water surface is also systematically investigated.

\section{Numerical Investigation and Results}

To investigate the hydrodynamic coefficients of the Shark-AUV, CFD simulations (including towing experiment simulation and PMM experiment simulation) are carried out to obtain the curves of the hydrodynamic loads versus the movement variables in different postures and motion conditions. To meet the requirements of the CFD method, the 3D model of the Shark-AUV is simplified as follows: (1) keeping the hull of the AUV, remove small appendages that have little effect on the overall performance of hydrodynamic performance investigation; (2) ignoring the internal structure of the AUV cabin. The size of the computational domain is $7 L \times 10 D \times 10 D(L=761.5 \mathrm{~mm}, D=220 \mathrm{~mm})$ to avoid blocking effects [34]. The simplified 3D model, the computational domain for CFD simulation are shown in Figure 3. And Figure 4 shows the meshing of the 3D model of the Shark-AUV, the number of mesh is set to 0.85 million by some experiments. As shown in Figure 5, the range of $y^{+}$value is 30 to 150 , which meets the requirements of the CFD simulation. 
Table 1 shows the setting of some initial parameters of the CFD simulation. The boundary conditions include velocity-inlet, outlet, wall, and symmetry. Velocity-inlet: forward, top and bottom of the domain, its value is defined by the user-defined files (UDF) file, we can observe the change of resistance by setting different velocity-inlet; Outlet: backward of the domain, pressure outlet; Wall: hull body, non-slip fixed wall; Symmetry: centerline boundary and side of the domain.

Table 1. Setting of some initial parameters of CFD simulation.

\begin{tabular}{ll}
\hline Parameters & Initial Setting of the Parameters \\
\hline Time & Steady (unsteady) motion is steady (transient) state \\
Turbulence model & RNG $k-\epsilon$ model \\
Discrete format & Second-order upwind discrete scheme \\
Solving algorithm & PISO \\
Fluid type & Liquid, density is $998.2 \mathrm{~kg} / \mathrm{m}^{3}$, others are default \\
Time step & 1500 steps in steady motion and 100 steps per cycle \\
& in unsteady motion \\
\hline
\end{tabular}
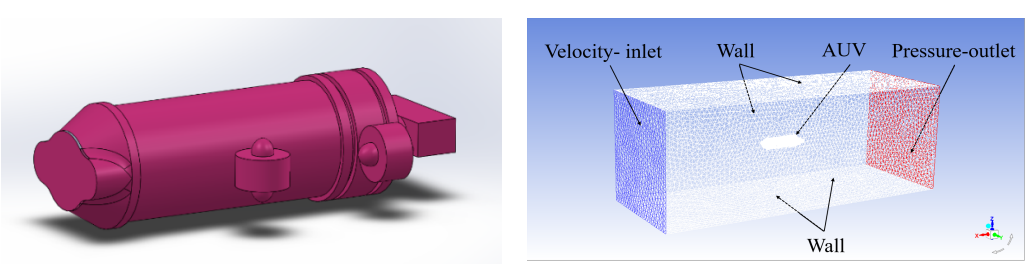

Figure 3. Left diagram shows the full-scale 3D model of the Shark-AUV; the right one shows the computational domain of the CFD simulation.
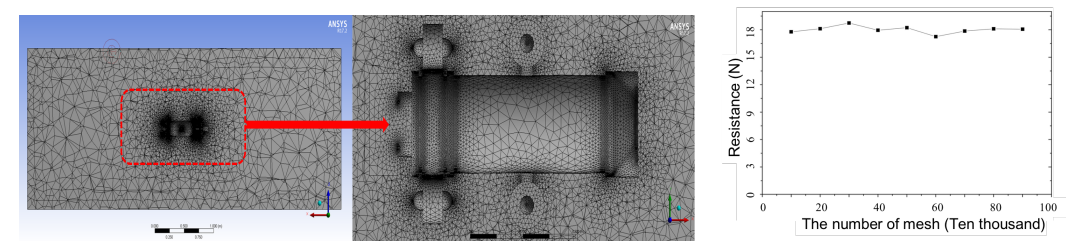

Figure 4. Left diagram shows meshing of the 3D model of the Shark-AUV; the right one shows the resistance of the AUV versus the number of meshes.

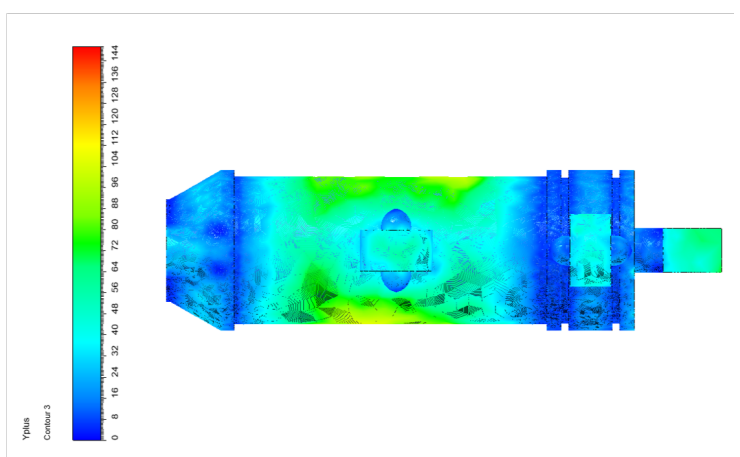

Figure 5. $y^{+}$value when the Shark-AUV cruises along the $+x$-direction at $0.5 \mathrm{~m} / \mathrm{s}$.

\subsection{Towing Experiment Simulation}

Towing experiment simulation is to simulate the steady motion of the Shark-AUV, including forward cruising along $x, y$, and $z$ axis, and oblique cruising. 


\subsubsection{Hydrodynamic Performance of Forward Cruising}

As shown in Figure 6, since the hull of the Shark-AUV is asymmetric with respect to the yoz plane, the flow around the AUV are different when cruising along the $\pm x$-directions. This means that the hydrodynamic forces of the AUV are also different when cruising along the $\pm x$-directions. To investigate hydrodynamic performance of forward cruising by CFD simulation, we consider the AUV cruising along the $\pm x$-directions, as shown in Figure 7 , the velocity-inlet ranges from $-1.2 \mathrm{~m} / \mathrm{s}$ to $1.2 \mathrm{~m} / \mathrm{s}$ (increasing step is $0.1 \mathrm{~m} / \mathrm{s}$ ), and the AUV model is static in the center of the computational domain. The curves of the hydrodynamic resistances versus velocity are fitted by the least squares algorithm, the value of the quadratic coefficients of the fitting curves are the hydrodynamic coefficients $\left(X_{u|u|^{\prime}}^{\prime}, X_{u u}^{\prime}, Y_{v|v|}^{\prime}, Z_{w|w|}^{\prime}\right)$ when the AUV cruising froward along $x, y, z$ axis. Similarly, the hydrodynamic coefficients $\left(X_{v v}^{\prime}, X_{w w}^{\prime}, M_{w w}^{\prime}, N_{v|v|}^{\prime}\right)$ can be obtained by analyzing the forces and moments when the AUV cruising forward along the $y$ and $z$ axis.
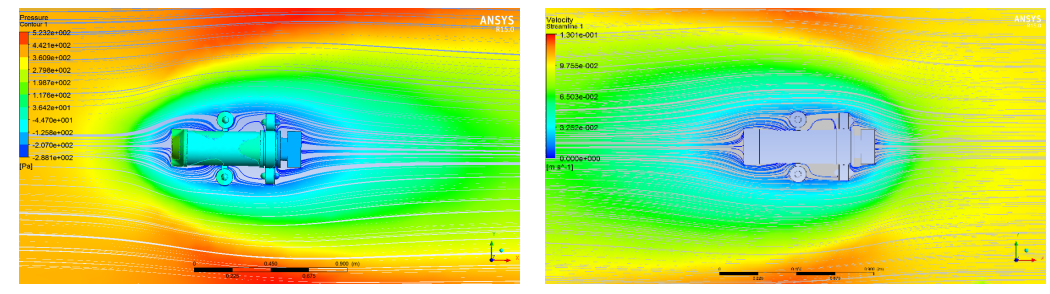

Figure 6. Left diagram shows the flow around Shark-AUV cruising along $+x$-direction; the right one shows flow around Shark-AUV cruising along $-x$-direction.
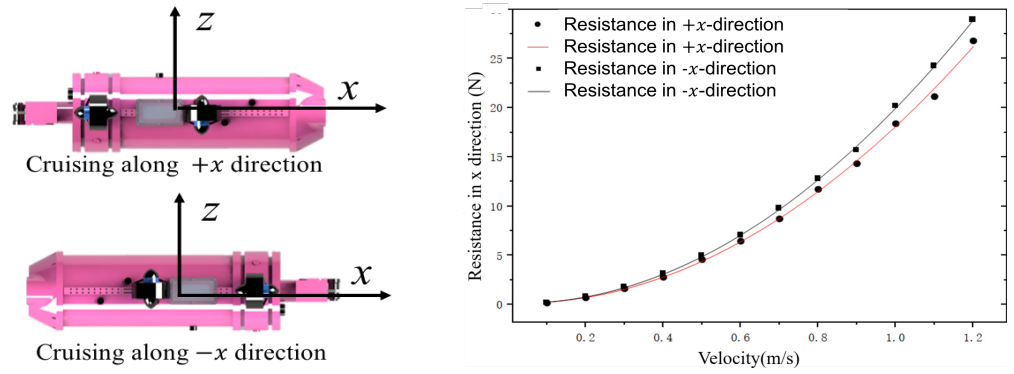

Figure 7. Left diagram shows the Shark-AUV cruising along $\pm x$-directions in a body reference frame; the right one shows the curves of hydrodynamic resistances versus velocity of the AUV cruising along $\pm x$-directions.

\subsubsection{Hydrodynamic Performance of Oblique Cruising}

Oblique cruising experiment simulation of the Shark-AUV model includes oblique cruising simulations in the horizontal plane, vertical plane, and space. As shown in Figure 8, the velocity of the AUV in oblique cruising can be divided into three components along the coordinate axis of the body-fixed frame

$$
\left\{\begin{array}{l}
u=U \cos \beta \cos \alpha \\
v=-U \sin \beta \\
w=U \cos \beta \sin \alpha
\end{array}\right.
$$

where $U$ is the velocity of the AUV, $\alpha$ is the attack angle, $\beta$ is the drift angle.

The setting of oblique cruising simulation is similar to that of forward cruising except that oblique cruising of the AUV has an additional drift angle or attack angle. As shown in Figure 8, the oblique cruising experiment simulation of the AUV in the horizontal plane is to put the AUV model into the computational domain at a certain angle around the $z$-axis (drift angle $\beta$ ), which brings a lateral velocity $v$ to the AUV. Setting the value of velocityinlet at $0.5 \mathrm{~m} / \mathrm{s}$ and $1 \mathrm{~m} / \mathrm{s}$, respectively, and the $\beta$ increased from $-20^{\circ}$ to $20^{\circ}$ (increasing 
step is $5^{\circ}$ ). Through CFD simulation, the resistance of the AUV in the $y$-direction and the resistance moment around the $x$-axis and the $z$-axis can be obtained. As shown in Figure 9, the lines of the hydrodynamic resistances (moments) versus drift angles at two different velocities are fitted by the least-squares algorithm, and then the slope of the fitted lines are subjected to the dimensionless normalization to obtain values of hydrodynamic coefficients $Y_{v}^{\prime}, Y_{0}^{\prime}, N_{v}^{\prime}, N_{0}^{\prime}$, and $K_{0}^{\prime}$. The oblique cruising simulation of the AUV in the vertical plane is similar to that in the horizontal plane (it has a certain drift angle around the $y$-axis). Oblique cruising in space is the superposition of oblique cruising in the horizontal plane and the vertical plane.
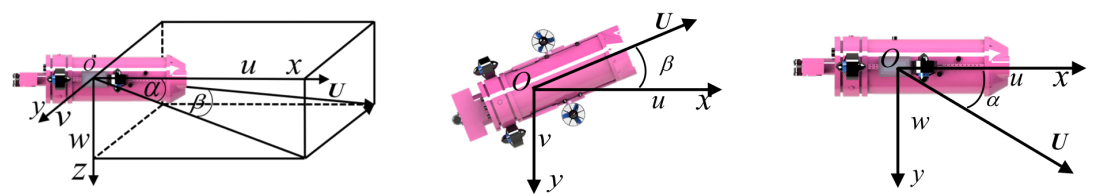

Figure 8. Left diagram shows hydrodynamic angles of the Shark-AUV; the middle diagram shows the oblique motion of the AUV in the horizontal plane; the right diagram shows the oblique motion of the AUV in the vertical plane.
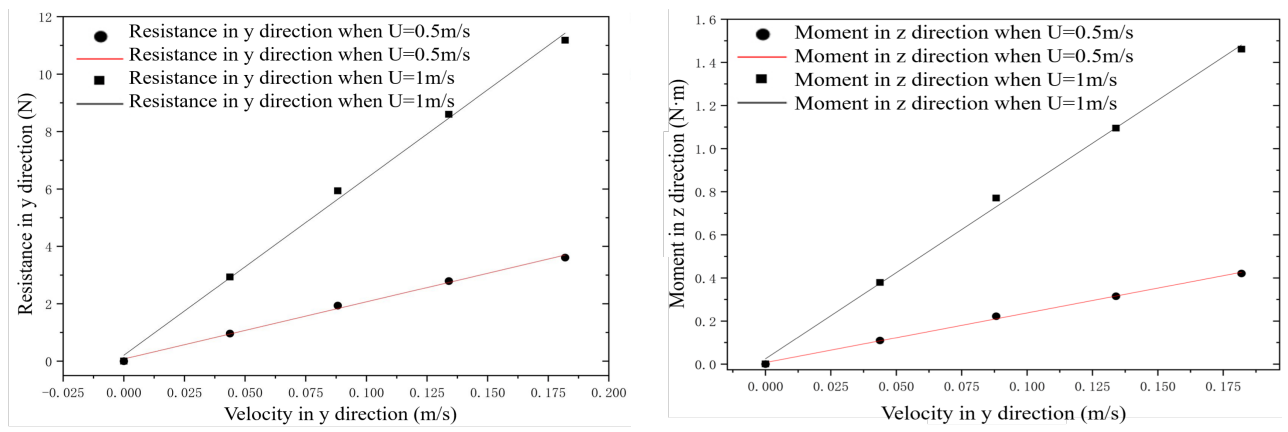

Figure 9. Left diagram shows the relationship of lateral resistance $Y$ versus lateral velocity $v$; the right diagram shows the relationship of roll moments $N$ versus lateral velocity $v$.

\subsection{PMM Experiment Simulation}

The PMM experiment simulation investigates the hydrodynamic performance of the Shark-AUV in unsteady motions, including heave, sway, pitch, roll, and yaw. In this work, we apply a dynamic mesh in the FLUENT module and combine the UDF to simulate these five motions. Figure 10 is the diagram of the heave motion, in the computational domain, the Shark-AUV not only faces the incoming flow, but also performs a vertical sinusoidal oscillation motion. This motion can be expressed as

$$
\left\{\begin{array}{l}
A=a \sin \omega t \\
\theta=\dot{\theta}=0 \\
w=\dot{A}=a \omega \cos \omega t \\
\dot{w}=-a \omega^{2} \sin \omega t
\end{array}\right.
$$

where $A, a$ and $\omega$ are the displacement, amplitude, and frequency of heave motion; $w$ and $w$ are the velocity and acceleration of the AUV; $\theta$ and $\dot{\theta}$ are angular velocity and angular acceleration of the AUV around the $y$-axis. Assuming that the vertical force on the AUV is $Z$, and the pitch moment is $M$, combined with the Equation (6), the hydrodynamic effects on the AUV can be expressed as 


$$
\left\{\begin{array}{l}
Z=Z_{\dot{w}} \dot{w}+Z_{w} w+Z_{0} \\
=-a \omega^{2} Z_{w} \sin \omega t+a \omega Z_{w} \cos \omega t+Z_{0} \\
M=M_{\dot{w}} \dot{w}+M_{w} w+M_{0} \\
=-a \omega^{2} M_{\dot{w}} \sin \omega t+a \omega M_{w} \cos \omega t+M_{0}
\end{array}\right.
$$

Since the heave motion of the Shark-AUV is a weak maneuvering motion, the values of parameters $a$ and $w$ are small and can be ignored in our work. After the dimensionless normalization, we can get the following expression

$$
\left\{\begin{array}{l}
\frac{Z_{a}}{0.5 \rho L^{2} V^{2}}=\frac{-a L \omega^{2}}{V^{2}} Z_{\dot{w}}^{\prime}, \frac{Z_{b}}{0.5 \rho L^{2} V^{2}}=\frac{a \omega}{V} Z_{w}^{\prime} \\
\frac{M_{a}}{0.5 \rho L^{3} V^{2}}=\frac{-a L \omega^{2}}{V^{2}} M_{w}^{\prime}, \frac{M_{b}}{0.5 \rho L^{3} V^{2}}=\frac{a \omega}{V} M_{w}^{\prime}
\end{array}\right.
$$

The heave motion simulation is to get the values of hydrodynamic coefficients $Z_{i w}^{\prime}, Z_{w}^{\prime}$, $M_{w}^{\prime}$, and $M_{w}^{\prime}$.

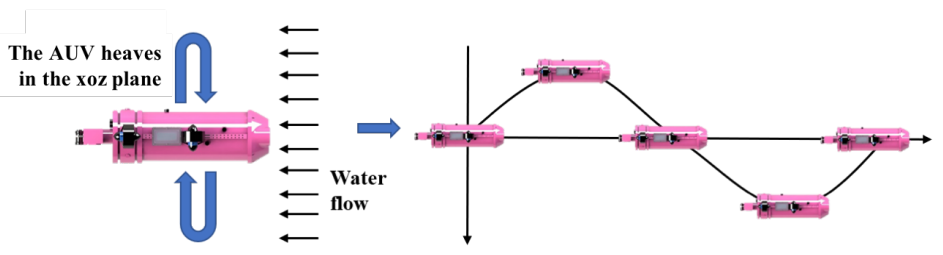

Figure 10. Schematic diagram of heave motion of the Shark-AUV.

In this simulation, the motion parameters of the Shark-AUV are determined by the UDF, and the setting of other parameters is the same as Table 1 . Here, the heave motion parameters of the AUV are set as: the amplitude $a=0.004 \mathrm{~m}$, the length $L=0.7615 \mathrm{~m}$, the longitudinal motion velocity $v=0.5 \mathrm{~m} / \mathrm{s}$, and the frequency $f=0.2,0.4,0.6,0.8,1$. Table 2 shows the numerical calculation results of the heave motion, and the hydrodynamic force $Z$ and moment $M$ of this motion can be obtained. The process of hydrodynamic coefficient estimation of the other four motions is similar to the heave motion. Through towing experiment simulation and PMM experiment simulation, all the unknown hydrodynamic coefficients in Equation (4) are estimated, and the results are summarized in Table 3.

Table 2. Numerical estimation of heave motion simulation of the Shark-AUV.

\begin{tabular}{cccccccc}
\hline$f(h z)$ & $w(\mathbf{1} / s)$ & $-a L w^{2} / V^{2}$ & $a w / V$ & $\frac{Z_{a}}{\mathbf{0 . 5 \rho L ^ { 2 } V ^ { 2 }}}$ & $\frac{Z_{b}}{\mathbf{0 . 5} \rho L^{2} V^{2}}$ & $\frac{M_{a}}{\mathbf{0 . 5 \rho L ^ { 3 } V ^ { 2 }}}$ & $\frac{M_{b}}{\mathbf{0 . 5 \rho L ^ { 3 } V ^ { 2 }}}$ \\
\hline 0.2 & 1.256 & -0.19240 & 0.10053 & 0.0198 & -0.0050 & -0.0055 & 0.0030 \\
0.4 & 2.513 & -0.76961 & 0.20106 & 0.0892 & -0.0202 & -0.0180 & 0.0088 \\
0.6 & 3.769 & -1.73162 & 0.30159 & 0.2011 & -0.0664 & -0.0240 & 0.0197 \\
0.8 & 5.026 & -3.07843 & 0.40212 & 0.3413 & -0.1011 & -0.0359 & 0.0376 \\
1 & 6.283 & -4.81005 & 0.50265 & 0.5016 & -0.1558 & -0.0397 & 0.0392 \\
\hline
\end{tabular}

\begin{tabular}{|c|c|c|c|c|c|c|c|c|c|c|c|}
\hline Coefficients & Value & Coefficients & Value & Coefficients & Value & Coefficients & Value & Coefficients & Value & Coefficients & Value \\
\hline$X_{q q}^{\prime}$ & -0.0131 & $Y_{v|r|}^{\prime}$ & 0.5076 & $K_{p q}^{\prime}$ & 0 & $X_{r r}^{\prime}$ & 0.0007 & $Y_{*}^{\prime}$ & 0.0009 & $K_{q r}^{\prime}$ & 0.0003 \\
\hline$X_{\dot{u}}^{\prime}$ & -0.3618 & $Y_{v}^{\prime \prime}$ & -0.6681 & $K_{p}^{\prime \prime}$ & -0.2036 & $X_{v r}^{\prime}$ & 0.0754 & $Y_{v|v|}^{\prime}$ & -0.1936 & $K_{v p}^{\prime \prime}$ & -0.0138 \\
\hline$X_{w q}^{\prime \prime}$ & -0.1043 & $Y_{v w}^{\prime}$ & -0.0948 & $K_{w p}^{\prime}$ & 0 & $X_{u u}^{\prime}$ & -0.0773 & $Z_{\dot{q}}^{\prime}$ & -0.0131 & $K_{w r}^{\prime}$ & 0.0138 \\
\hline$X_{v v}^{\prime}$ & 0.0147 & $Z_{p r}^{\prime}$ & -0.0007 & $K_{*}^{\prime}$ & 0 & $X_{w w}^{\prime}$ & -0.0227 & $Z_{w}^{\prime}$ & -0.1043 & $K_{v w}^{\prime}$ & -0.0289 \\
\hline$Y_{\dot{r}}^{\prime}$ & -0.0007 & $Z_{v p}^{\prime}$ & -0.0754 & $M_{\dot{q}}^{\prime}$ & 0.0044 & $Y_{\dot{p}}^{\prime}$ & 0 & $Z_{q}^{\prime}$ & -0.1550 & $M_{p r}^{\prime}$ & -0.0219 \\
\hline$Y_{p q}^{\prime}$ & 0.0131 & $Z_{*}^{\prime}$ & -0.0017 & $M_{w}^{\prime}$ & -0.0056 & $Y_{\dot{v}}^{\prime}$ & -0.0754 & $Z_{w}^{\prime}$ & -0.3805 & $M_{v p}^{\prime \prime}$ & 0.0852 \\
\hline$Y_{w p}^{\prime \prime}$ & 0.1043 & $Z_{w w}^{\prime}$ & -0.3467 & $M_{v p}^{\prime \prime}$ & 0.0852 & $Y_{r}^{\prime}$ & -0.0852 & $K_{\dot{p}}^{\prime}$ & -0.0172 & $M_{q}^{p}$ & -0.0718 \\
\hline$M_{*}^{\prime}$ & 0.0003 & $M_{w w}^{\prime}$ & 0.0351 & $M_{w}^{\prime}$ & -0.1126 & $N_{\dot{r}}^{\prime}$ & 0.0047 & $N_{\dot{p}}^{\prime}$ & 0 & $N_{p q}^{\prime}$ & 0.0216 \\
\hline$N_{q r}^{\prime}$ & 0 & $N_{\dot{v}}^{\prime}$ & 0.0043 & $N_{r}^{\prime}$ & -0.0179 & $N_{w p}^{\prime}$ & -0.0131 & $N_{v|r|}^{\prime}$ & -0.3389 & $N_{*}^{\prime}$ & 0.0001 \\
\hline$N_{v}^{\prime}$ & 0.0391 & $N_{v|v|}^{\prime}$ & 0.0097 & & & & & & & & \\
\hline
\end{tabular}

Table 3. Summary of the estimated hydrodynamic coefficients by towing experiment and PMM experiment simulation. 


\subsection{Hydrodynamic Performance Analysis near Water Surface}

In this section, based on the potential flow theory [35], the hydrodynamic performances of the Shark-AUV in regular and irregular waves are studied by the CFD method. Schematic diagram of the AUV subjected to surface waves is shown in Figure 11. The AUV is designed to cruise in the underwater environment, though the AUV may sometimes work near the surface waves due to the shallow water, it does not work in the two-phase air-water environment. Therefore, only the influence of wave frequency, wave amplitude and submerged depth on the dynamic performance of the AUV is analyzed. In addition, compared with the wavelength, the size of the AUV is small. Therefore, the viscous force is ignored and only the inertial force is considered.

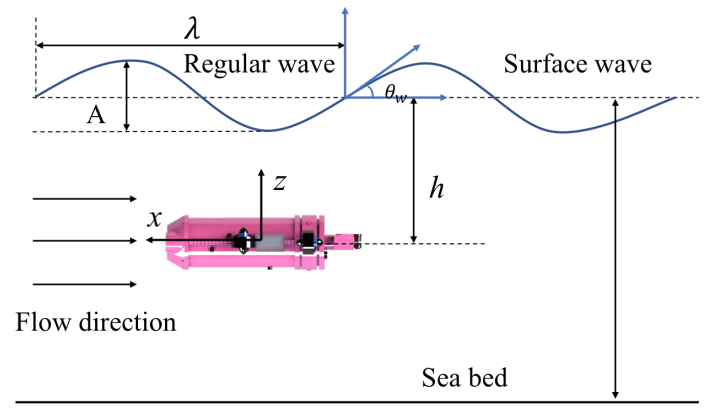

Figure 11. Schematic diagram of the Sharks-AUV subjected to surface waves.

\subsubsection{Hydrodynamic Performance Analysis under Regular Waves}

This section mainly analyzes the first-order wave force, amplitude response factor (RAO), and second-order wave force of the Shark-AUV when cruising at different submerged depths in regular waves.

(1) Analysis of first-order wave forces at different submerged depths. Figure 12 shows the 3D panel model of the Shark-AUV and the meshing of the model, which is used to investigate the hydrodynamic performance of the AUV in first-order waves. In this simulation, the AUV was designed to cruise at different velocities $(0 \mathrm{~m} / \mathrm{s}, 0.5 \mathrm{~m} / \mathrm{s}$, and $1 \mathrm{~m} / \mathrm{s})$, different submerged depths $(h=0.6 \mathrm{~d}, 0.7 \mathrm{~d}, 0.8 \mathrm{~d}, 0.9 \mathrm{~d}, 1.0 \mathrm{~d}, 2.0 \mathrm{~d}, 4.0 \mathrm{~d}, 6.0 \mathrm{~d}$, $8.0 \mathrm{~d}, \mathrm{~d}=220 \mathrm{~mm})$, and different wavelengths $(\lambda$ ranges from $0.5 l$ to $50 l(l=761.5 \mathrm{~mm}))$. Figure 13 shows the surface pressure nephogram of the AUV at different submerged depths when the AUV moves in a head wave and is located in the trough with a wave amplitude of $0.4 \mathrm{~m}$. The first-order wave forces in the longitudinal, vertical, and pitch directions under different motion parameters are shown in Figure 14. The maximum longitudinal force, vertical force, and pitching moment of the AUV under different submerged depths are represented in Figure 15. We can see that: (1) when the AUV cruises near the water surface at different velocities, the longitudinal force has two or more peaks as the wavelength increases, and the longitudinal force of the last peak is the maximum; (2) when the AUV cruises in the surface waves at different speeds, the faster the speed is, the longer the wavelength when the vertical force and pitching moment reach the peak value; (3) all the longitudinal force, vertical force, and pitching moment on the AUV show an exponential decrease with the increase of the submerged depth. Figure 16 shows the surface pressure nephogram of the AUV at different wave frequencies when the AUV moves in a head wave and is located in the trough with a wave amplitude of $0.4 \mathrm{~m}$. Taking the position of the AUV in the trough wave as an example, Figure 17 shows the surface pressure nephogram of the AUV at different wave frequencies when the amplitude of the wave is $0.4 \mathrm{~m}$, moving in head waves. We can see that the higher the wave frequency, the more uneven the surface pressure on the AUV, and the peak value increases first and then decreases. The wavelength of a regular wave is inversely proportional to $f^{2}$. Long-wave represents low-frequency wave, which is consistent with the trend of numerical estimation results of the first-order wave force. 

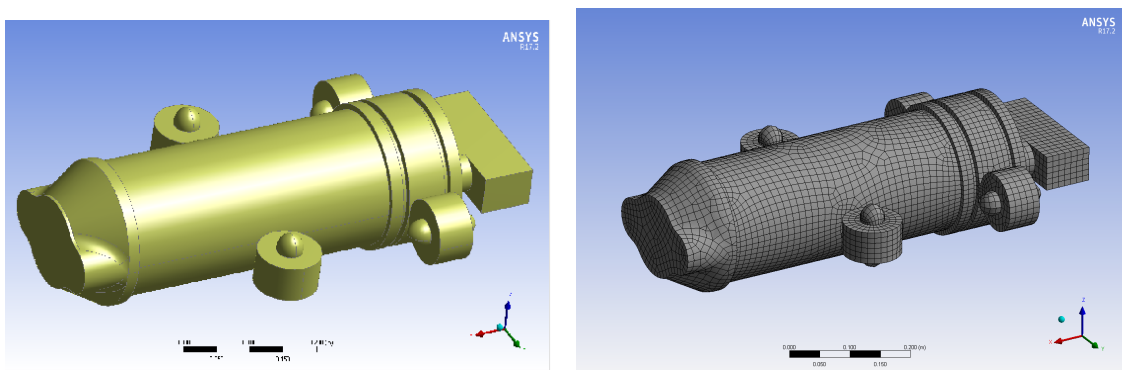

Figure 12. Panel model of the Shark-AUV and meshing of the model.
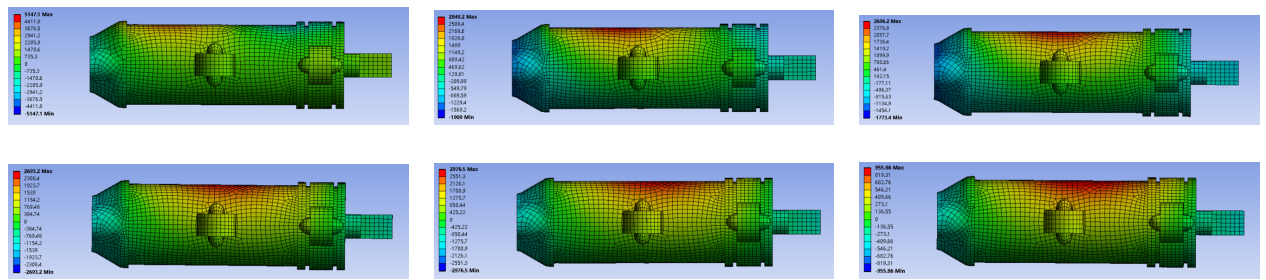

Figure 13. From top to bottom, from left to right: surface pressure nephogram of the Shark-AUV at different submerged depths ( $h=0.6 \mathrm{~d}, 0.7 \mathrm{~d}, 0.8 \mathrm{~d}, 0.9 \mathrm{~d}, 1 \mathrm{~d}, 2 \mathrm{~d})$ when the AUV moves in a head wave and is located in the trough with a wave amplitude of $0.4 \mathrm{~m}$.
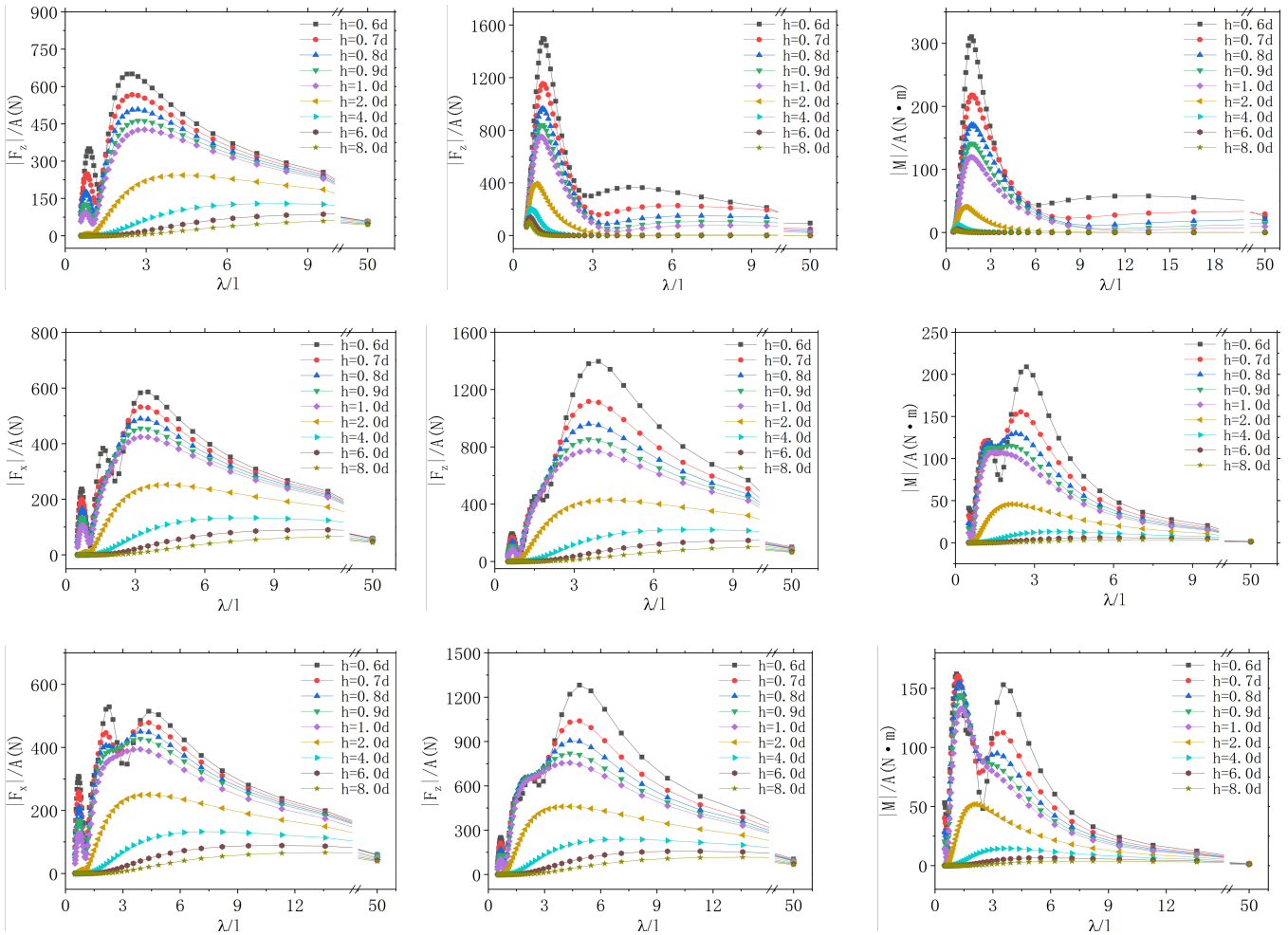

Figure 14. Curves of wave force versus velocity of the Shark-AUV at different submerged depths. From the left column to the right column are the longitudinal force, vertical force and pitch moment of the AUV at the speeds of $0 \mathrm{~m} / \mathrm{s}, 0.5 \mathrm{~m} / \mathrm{s}$ and $1 \mathrm{~m} / \mathrm{s}$. 

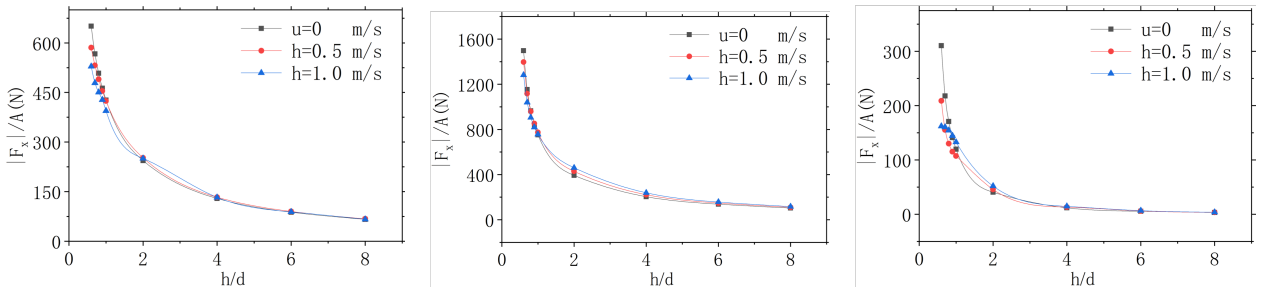

Figure 15. From left to right: maximum longitudinal force, vertical force, and pitch moment at different submerged depths.
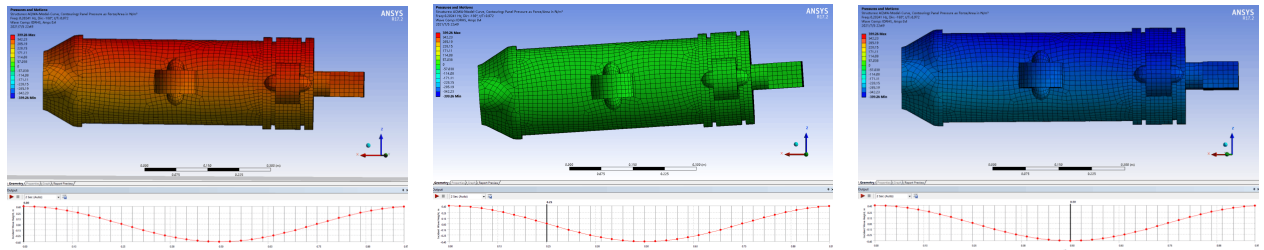

Figure 16. Surface pressure nephogram of the Shark-AUV at different location of the wave, from left to right: crest, balance state, and trough.
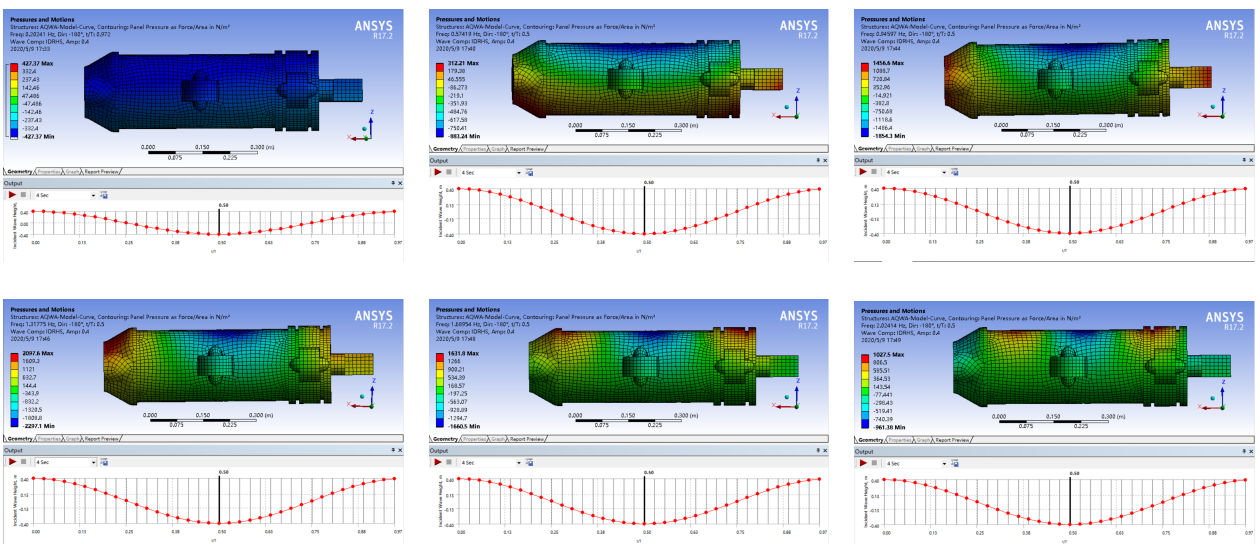

Figure 17. From top to bottom, from left to right: surface pressure nephogram of the Shark-AUV at different wave frequencies ( $\mathrm{f}=0.20241 \mathrm{~Hz}, 0.57419 \mathrm{~Hz}, 0.94597 \mathrm{~Hz}, 1.31775 \mathrm{~Hz}, 1.58594 \mathrm{~Hz}, 2.02414 \mathrm{~Hz}$ ) when the AUV moves in a head wave and is located in the trough with a wave amplitude of $0.4 \mathrm{~m}$.

(2) Analysis of second-order wave forces at different submerged depths. The secondorder wave forces in longitudinal, vertical, and pitch directions at different submerged depths $(\mathrm{h}=2.0 \mathrm{~d}, 4.0 \mathrm{~d}, 6.0 \mathrm{~d}$, and $8.0 \mathrm{~d})$ and different wavelength $(\lambda / 1=0.5-50)$ are analyzed. The results are shown in Figure 18. It can be seen that: (1) the second-order wave force of the longitudinal direction is proportional to the wavelength and inversely proportional to the submerged depth; (2) when the AUV near the water surface (the submerged depth is small), the peak of the vertical second-order wave force appears at a short wavelength and then gradually decreases as the wave wavelength increases; when the AUV is far from the water surface (the submerged depth is large), the wave force increases slowly and then reaches stability, and the motion of the AUV is less affected by the second-order wave force; (3) the characteristics of the second-order wave force in the pitch motion are the same as those in the vertical direction. The overall trend is that the second-order average wave force is proportional to the wavelength. 

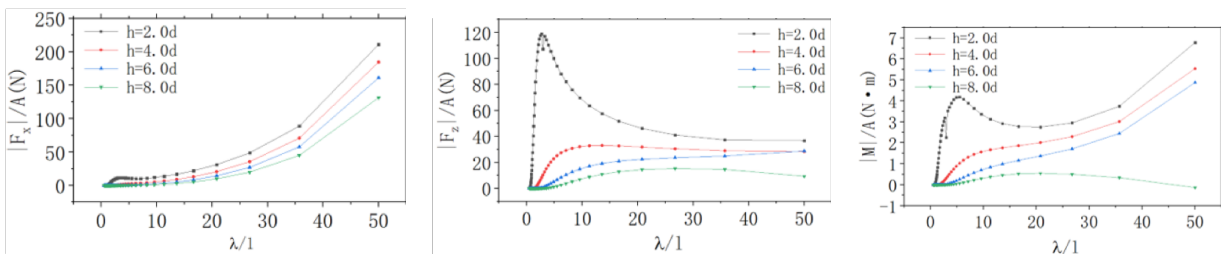

Figure 18. From left to right: second-order wave forces of the Shark-AUV in longitudinal, vertical, and pitch directions at different submerged depths and different wavelengths.

(3) RAO analysis at different submerged depths. When the AUV is subjected to wave force, its motion will change due to the wave force. The ratio of the motion response amplitude in each direction to the unit amplitude is called the amplitude response factor (RAO) in our work. The RAO analysis can help the AUV predict the wave force of each direction before carrying out underwater tasks, which is important for the design of control strategies. Figure 19 shows curves of RAO in the surge, heave, and pitch direction versus wavelength when AUV cruises at $0 \mathrm{~m} / \mathrm{s}$. The characteristics of the surge/heave $\mathrm{RAO}$ are: as the wavelength increases, RAO reaches a small peak, then increases sharply, and finally increases slowly. The characteristics of the pitch RAO change are: as the wavelength increases, RAO first reaches a small peak, then increases sharply, then drops sharply, and finally drops slowly.
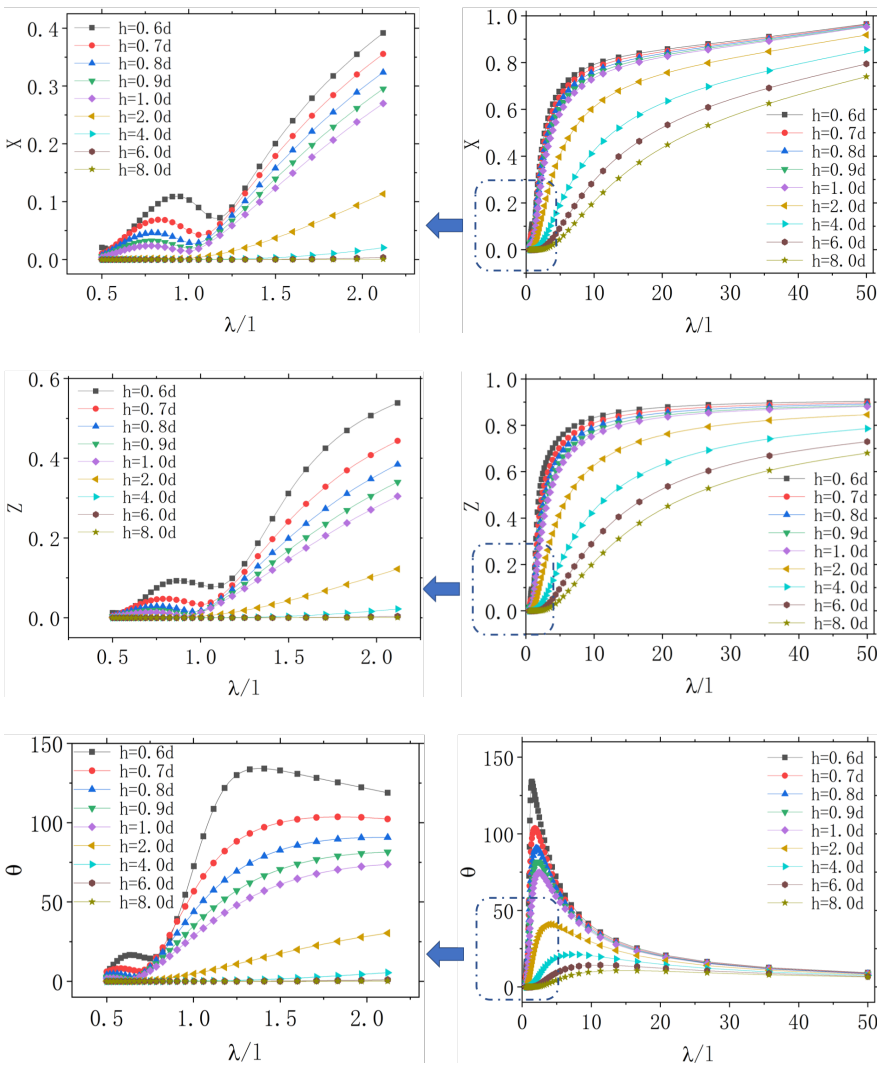

Figure 19. From top to bottom: Curves of surge RAO, heave RAO, and pitch RAO versus wavelength.

3.3.2. Hydrodynamic Performance Analysis under Irregular Waves

Based on the irregular wave theory in [36], the irregular waves can be expressed as

$$
A(t)=\sum_{k=1}^{n} A_{k} \cos \left(\omega_{k} t+\varepsilon_{k}\right)
$$


where $A$ is the wave height at one of the wave surfaces, $A_{k}$ is the wave height of the $k$-th regular wave, $\omega_{k}$ is the circular frequency of the $k$-th regular wave, and $\varepsilon_{k}$ is the phase of the $k$-th regular wave.

The irregular wave at a certain moment can be regarded as the superposition of multiple different regular waves. The wave spectrum used in this paper is the PM (PiersonMoskowitz) dual-parameter wave spectrum [37], it can be expressed as

$$
S_{i}(\omega)=\frac{173 H_{s}^{2}}{T_{1}^{4}} \omega^{-5} \exp \left(\frac{-692 H_{s}^{2}}{T_{1}^{4}} \omega^{-5}\right)
$$

where $T_{1}$ is the wave period, and the relationship with the peak period $\left(T_{p}\right)$ is $T_{1}=1.296 T_{p}$, $H_{S}$ is the significant wave height, and $\omega$ is the circular frequency of wave.

Figure 20 shows the surface wave under the PM dual-parameter spectrum when the significant wave height is $0.1 \mathrm{~m}, 0.3 \mathrm{~m}$, and $0.5 \mathrm{~m}$. It can be seen that the wave forms are almost the same, with only a certain difference in amplitude, which proves the effectiveness of our method. Figure 21 shows the peak value of the vertical displacement and pitch angle of the AUV versus the significant wave height in the time domain. It can be seen that when the AUV cruises under irregular waves, the vertical displacement and pitch angle can reach the maximum and minimum with the increase of wave height. Meanwhile, the vertical displacement and pitch angle of the AUV are large due to the small size of the AUV, the control stability of the AUV near the water surface is poor.
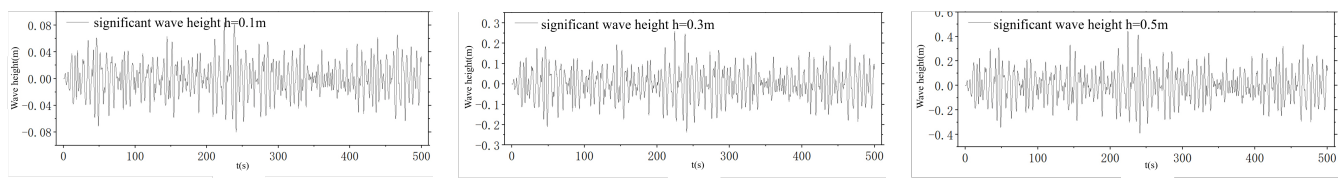

Figure 20. From left to right: wave surface curve of PM dual-parameter spectrum under different significant wave heights $(0.1 \mathrm{~m}, 0.3 \mathrm{~m}, 0.5 \mathrm{~m})$.
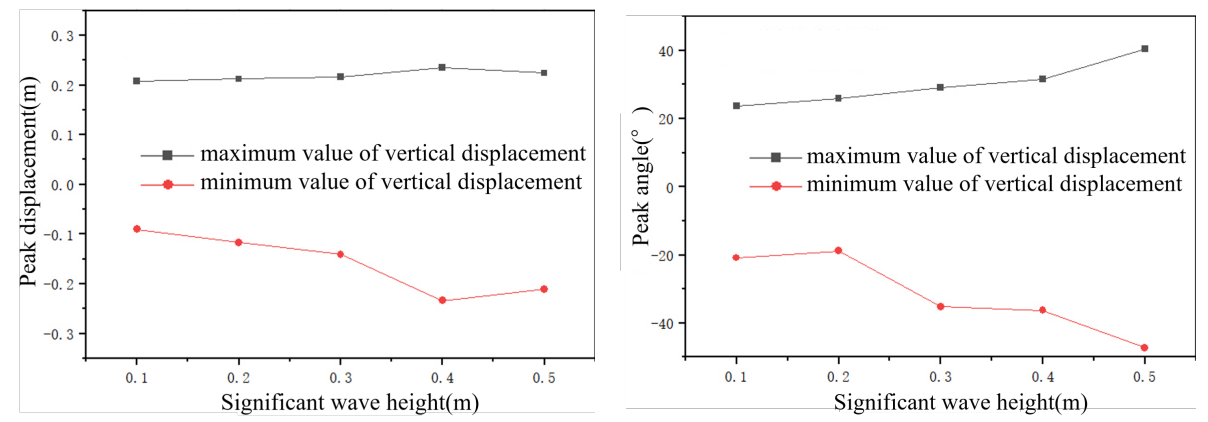

Figure 21. Curves of the maximum vertical displacement and pitch angle of the Shark-AUV versus the significant wave height.

\section{Experiments and Analysis}

\subsection{Validation of CFD Simulation}

\subsubsection{Validation of the Towing Experiment Simulation}

To validate the effectiveness of our towing experiment simulation, we use our method to estimate the hydrodynamic coefficients of the SUBOFF model and then compare the results of our method with that of the standard experiment in [38]. As shown in Figure 22, the SUBOFF model without appendage is defined by three sections: the forbody $(1.016 \mathrm{~m})$, parallel middle body $(2.229 \mathrm{~m})$, and afterbody $(1.111 \mathrm{~m})$, total body length is $4.356 \mathrm{~m}$, and the maximum body diameter is $0.508 \mathrm{~m}$. The experiment setting in our work is consistent with that of the standard experiment NSWCCD [38], the speed of the SUBOFF model is set to 5.92 knots, 10.00 knot, 11.84 knots, 13.92 knots, 16.00 knot, and 17.99 knots, respectively. The experimental results are shown in Table 4, we can see that the maximum error 
of the RNG $k-\epsilon$ turbulence model is $5.94 \%$, and the standard deviation is 18.8 . In addition, based on the SUBOFF model, we also compare the effects of the RNG $k-\epsilon$ turbulence model and SST $k-\omega$ turbulence model on the calculation accuracy. The results are also shown in Table 4, the maximum error of the SST $k-\omega$ turbulence model is $2.67 \%$, and the standard deviation is 9.6. Thus, the accuracy of the SST $k-\omega$ turbulence model outperforms the RNG $k-\epsilon$ turbulence model in most cases. However, SST $k-\omega$ turbulence model requires a higher calculation cost. Our method needs to consider both calculation cost and calculation accuracy. Therefore, we choose the RNG $k-\epsilon$ turbulence model as a compromise in the numerical investigation method.

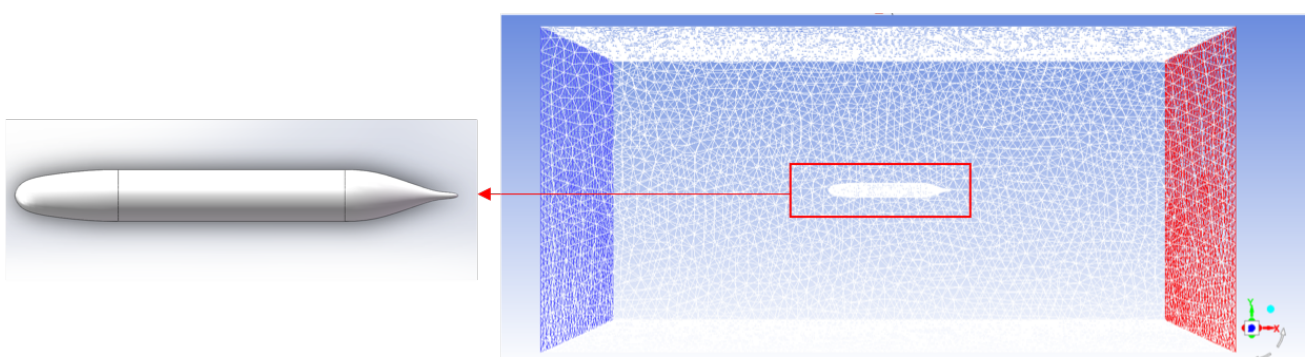

Figure 22. SUBOFF model without appendage and its computational domain.

Table 4. Comparison the result of our method with that of the NSWCCD [38].

\begin{tabular}{ccccccc}
\hline Speed (kont) & $\mathbf{5 . 9 2}$ & $\mathbf{1 0 . 0 0}$ & $\mathbf{1 1 . 8 4}$ & $\mathbf{1 3 . 9 2}$ & $\mathbf{1 6 . 0 0}$ & $\mathbf{1 7 . 9 9}$ \\
\hline NSWCCD results (N) & 87.4 & 242.2 & 332.9 & 451.5 & 576.9 & 697.0 \\
RNG k- $\epsilon$ results (N) & 92.59 & 244.86 & 335.84 & 454.76 & 590.63 & 736.10 \\
Error(\%) & 5.94 & 1.10 & 0.88 & 0.72 & 2.38 & 5.61 \\
SST k- $\omega$ results (N) & 89.73 & 237.71 & 325.85 & 441 & 573.38 & 713.01 \\
Error(\%) & 2.67 & 1.85 & 2.12 & 2.33 & 0.78 & 2.3 \\
\hline
\end{tabular}

\subsubsection{Validation of the PMM Experiment Simulation}

To validate the effectiveness of the PMM experiment simulation, we conduct a comparative experiment based on a standard ellipsoid. Figure 23 shows the 3D model of the standard ellipsoid model and its position in the computational domain. Taking the heave motion of the standard ellipsoid as an example, dynamic mesh and UDFs are applied to simulate this motion: the amplitude of the heave motion of the standard ellipsoid is $0.04 \mathrm{~m}$, the velocity-inlet is $0.5 \mathrm{~m} / \mathrm{s}$, and the heave frequency of the standard ellipsoid is $0.2,0.4,0.6,0.8$ and 1.0, respectively. As shown in Table 5, the experimental results of our method are compared with the reported results in [39]. We can see that the hydrodynamic coefficients obtained by our method meet the requirements. Although some hydrodynamic coefficients have small deviations, the overall estimated results have high reliability, which demonstrates the effectiveness of our method.

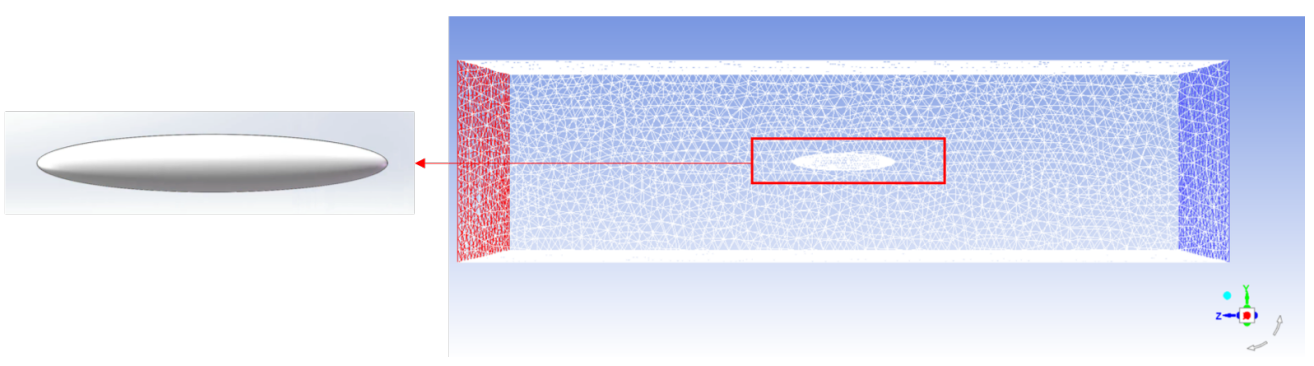

Figure 23. Standard ellipsoid model and its computational domain. 
Table 5. Comparison of results of our method with the experiment in [39].

\begin{tabular}{ccccc}
\hline Hydrodynamic Coefficient & $\boldsymbol{Z}_{\boldsymbol{w}}^{\prime}$ & $\mathbf{Z}_{\boldsymbol{w}}^{\prime}$ & $\boldsymbol{M}_{\boldsymbol{w}}^{\prime}$ & $\boldsymbol{M}_{\boldsymbol{w}}^{\prime}$ \\
\hline Numerical solution & -0.0266 & -0.0230 & $-8.466 \times 10^{-5}$ & 0.0232 \\
Standard solution & -0.0268 & -0.0186 & 0 & 0.0186 \\
Error (\%) & 0.7 & 23.7 & 0 & 24.7 \\
\hline
\end{tabular}

\subsubsection{Validation of Hydrodynamic Performance Analysis Method in Surface Waves}

To verify the effectiveness of our method for analyzing the hydrodynamic performance of Shark-AUV in surface waves, we use the ANSYS AQWA to replicate the experiment reported in [40], and then compared the results of our method to the experimental results reported in [40]. As shown in Figure 24, the object in [40] is a torpedo-shaped AUV model named $21 \mathrm{UUV}$, and parameters of the $21 \mathrm{UUV}$ and the setting of the reported experiment are shown in Table 6 . Figure 25 shows the relationship between the longitudinal force, vertical force and pitch moment of the 21UUV model and the wave frequency when $u=0 \mathrm{~m} / \mathrm{s}$, $0.489 \mathrm{~m} / \mathrm{s}, 0.733 \mathrm{~m} / \mathrm{s}$. It can be seen that there is a small deviation between the estimated results of our method and the ground truth in [40], most of the results of our method can reflect the variation trend of the force (moment) of the 21UUV model with the ocean wave circle frequency, which demonstrates that our method has great significance and can be used to estimate wave forces of the AUV.

Table 6. Parameters of the 21UUV and the reported experiment.

\begin{tabular}{ll}
\hline Parameters & Parameters Setting \\
\hline Size & $L=1.786 \mathrm{~m}, D=0.27 \mathrm{~m}$ \\
Distance to the sea surface & $0.379 \mathrm{~m}$ \\
sailing speed in the surface waves & $u_{1}=0 \mathrm{~m} / \mathrm{s}, u_{2}=0.489 \mathrm{~m} / \mathrm{s}, u_{3}=0.733 \mathrm{~m} / \mathrm{s}$ \\
Amplitude of the waves & $A_{1}=0.014 \mathrm{~m}, A_{2}=0.028 \mathrm{~m}, A_{3}=0.037 \mathrm{~m}$ \\
Circle frequency range of the waves & $w=1.200$ to $7.207 \mathrm{rad} / \mathrm{s}$ \\
\hline
\end{tabular}

Figure 24. 3D model of the 21UUV. 

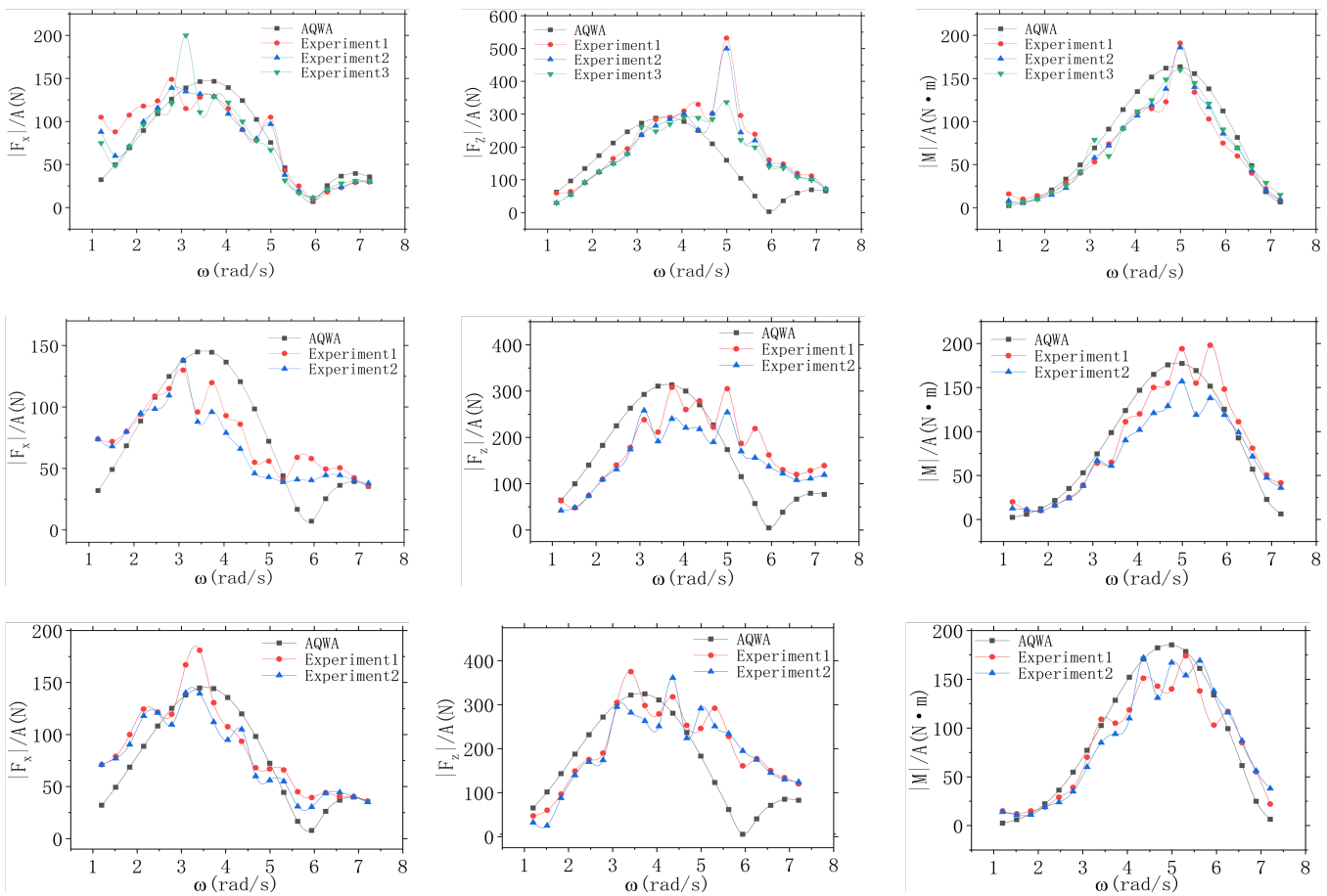

Figure 25. Verification of numerical investigation results of wave force based on the 21UUV model. From the top row to the bottom row: curves of the longitudinal force, vertical force and pitching moment versus the wave circular frequency when $u=0 \mathrm{~m} / \mathrm{s}, 0.489 \mathrm{~m} / \mathrm{s}, 0.733 \mathrm{~m} / \mathrm{s}$.

\subsection{Establishment of Physical Experimental platform}

\subsubsection{Design of Physical Experimental Platform}

As shown in Figure 26, the designed physical experiment platform is a tank pool with size of $4.12 \mathrm{~m} \times 2.01 \mathrm{~m} \times 1.22 \mathrm{~m}$ and with a aluminum frame. The synchronized linear module is consisted of a synchronized belt, a servo motor, and a guide rail. The servo motor drives the slider to move on the guide rail with a minimum speed of $0.003 \mathrm{~m} / \mathrm{s}$ and a maximum speed of $6 \mathrm{~m} / \mathrm{s}$, the Shark-AUV is connected to the slider by a sword. A six-dimensional force sensor is equipped on the sword to collect forces and moments.

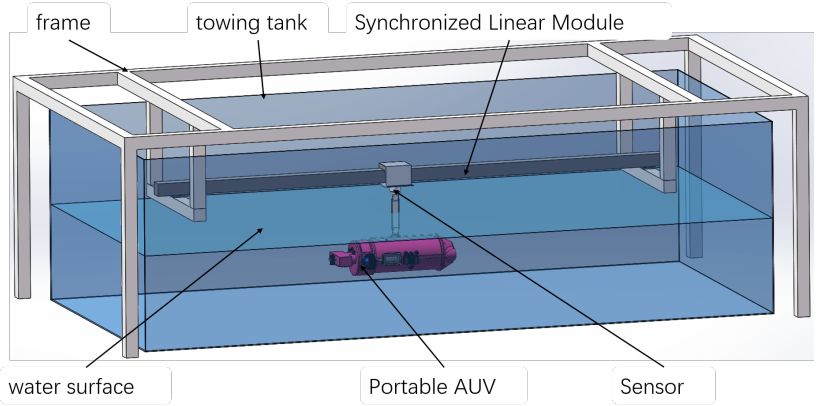

Figure 26. Framework introduction of the designed physical experiment platform.

\subsubsection{Validation of Physical Experimental Platform}

To evaluate the reliability of the established experiment platform, the towing experiments are conducted based on the standard SUBOFF model (scaling ratio is 1:8) in this tank. As shown in Figure 27, the SUBOFF model is fixed on the sword through the connector. The SUBOFF model moved at a speed ranged from $0.6 \mathrm{~m} / \mathrm{s}$ to $1.3 \mathrm{~m} / \mathrm{s}$ (increasing step is $0.09 \mathrm{~m} / \mathrm{s}$ ). The collected data of our experimental platform is compared with those reported in [38], as shown in Figure 28. It can be seen that the collected data of the estab- 
lished experiment platform are consistent with the reported standard experimental results, indicating that the established experiment platform is highly reliable.

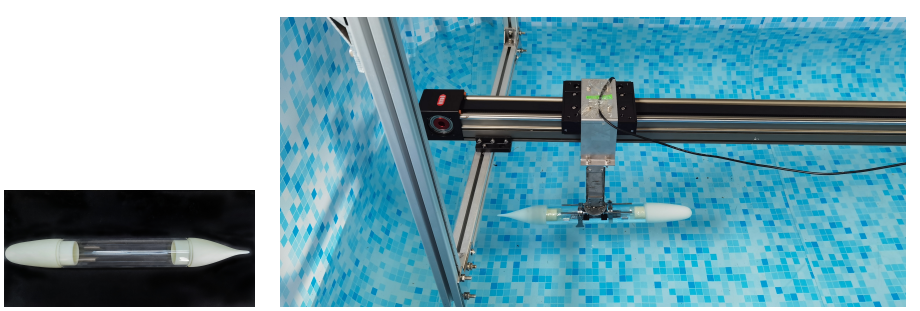

Figure 27. SUBOFF model and its towing experiment setup in our physical experiment platform.

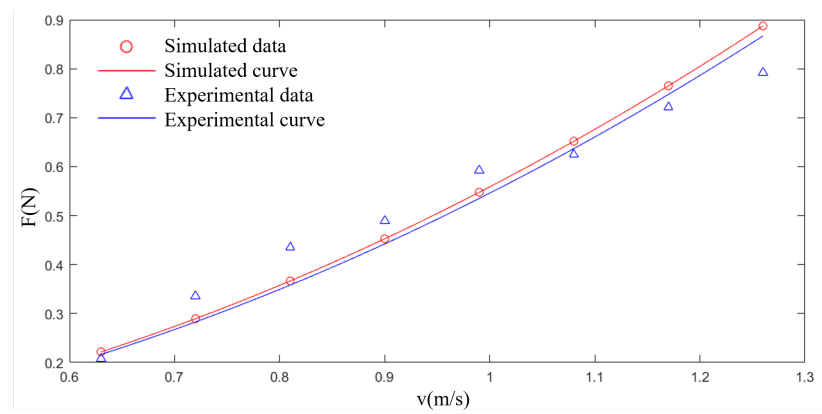

Figure 28. Comparison of physical experimental results and CFD simulation results based on the SUBOFF model.

4.2.3. Hydrodynamic Performance Investigation of the Shark-AUV Based on Our Physical Experiment Platform

An experimental evaluation method was proposed based on the established physical experiment platform to investigate the hydrodynamic coefficients of the Shark-AUV. Figure 29 shows the towing experiment of the AUV cruising forward along $x$ - and $y$ direction. The speed of the AUV for the forward cruising along $\pm x$-directions from $0.09 \mathrm{~m} / \mathrm{s}$ to $0.51 \mathrm{~m} / \mathrm{s}$, with an increasing step of $0.03 \mathrm{~m} / \mathrm{s}$. The speed of the AUV for the forward cruising along $y$ axis in the experiment ranges from $0.09 \mathrm{~m} / \mathrm{s}$ to $0.3 \mathrm{~m} / \mathrm{s}$, increasing at a step of $0.03 \mathrm{~m} / \mathrm{s}$. Associated hydrodynamic coefficients of the AUV are obtained by fitting the data collected by the six-dimensional force sensor, as shown in Figure 30. It can be seen that the hydrodynamic coefficients obtained by the established experiment platform are consistent with the reported results. Due to the simplification of the AUV model, the overall deviation of the two experimental results remains at a constant value, which indicates that the established experimental platform can effectively study the basic hydrodynamic performance of AUVs.
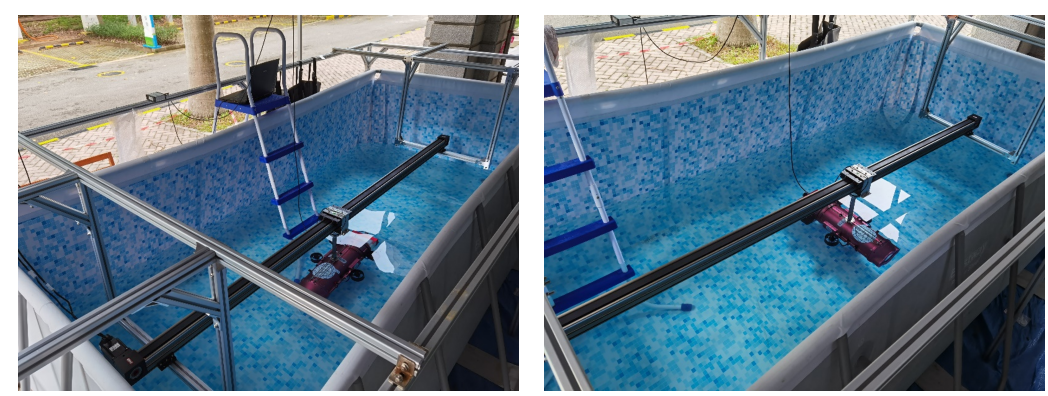

Figure 29. Hydrodynamic coefficient estimation of the Shark-AUV based on the established physical experiment platform. The left diagram shows cruising forward along the $x$-direction, and the right one shows cruising forward along the $y$-direction. 

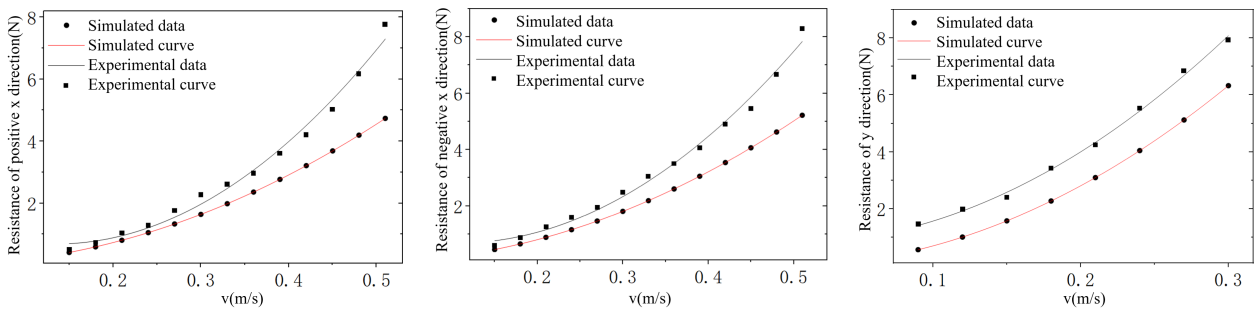

Figure 30. Comparison of hydrodynamic coefficients obtained by CFD method and physical experiment platform. From left to right: the comparison results in $+x$-direction, the comparison results in $-x$-direction, and the comparison results in $y$-direction.

\section{Conclusions}

In this work, we have conducted the most comprehensive hydrodynamic performance investigation on a new designed portable AUV. Based on the equations of motion of the AUV, all unknown hydrodynamic coefficients were numerically estimated by different experimental simulations of the AUV in the underwater environment with the CFD method. In addition, we also analyzed the hydrodynamic performance of the AUV cruising near the water surface. The wave force was taken as the external force to the dynamic model of the AUV, and it was systematically analyzed under different wave conditions. To verify the effectiveness of our method, some comparative experiments were conducted based on standard models. A physical experimental platform was built in our work for investigating the hydrodynamic performance of the portable AUV, and the effectiveness of the experimental platform was also verified. This physical experimental platform can be further used as an experimental evaluation method to investigate the hydrodynamic performance of other types of portable AUVs. In future work, we hope to extend the results of this research to the shape design and advanced control strategy design of portable AUVs.

Author Contributions: Conceptualization, L.H. and R.F.; methodology, L.H.; software, R.F.; validation, L.H., R.F. and X.C.; formal analysis, X.W.; investigation, L.H.; resources, X.W.; data curation, L.H.; writing — original draft preparation, L.H.; writing - review and editing, X.W.; visualization, L.H.; supervision, X.W.; project administration, X.W.; funding acquisition, X.W. All authors have read and agreed to the published version of the manuscript.

Funding: This work was supported in part by the Special Project for Research and Development in Key areas of Guangdong Province (No.2019B090920001), and Shenzhen Bureau of Science Technology and Information of China (No.JCYJ20180306172134024).

Institutional Review Board Statement: Not applicable.

Informed Consent Statement: Not applicable.

Conflicts of Interest: The authors declare no conflict of interest.

\section{References}

1. Locker, T. Water Dance; Houghton Mifflin Harcourt: Boston, MA, USA, 1997; Volume 132.

2. Jaffe, J.S.; Franks, P.J.; Roberts, P.L.; Mirza, D.; Schurgers, C.; Kastner, R.; Boch, A. A swarm of autonomous miniature underwater robot drifters for exploring submesoscale ocean dynamics. Nat. Commun. 2017, 8, 1-8. [CrossRef] [PubMed]

3. Yuh, J. Design and control of autonomous underwater robots: A survey. Auton. Robot. 2000, 8, 7-24. [CrossRef]

4. Botelho, S.; Neves, R.; Taddei, L. Localization of a fleet of auvs using visual maps. In Proceedings of the Europe Oceans 2005, Brest, France, 20-23 June 2005; Volume 2, pp. 1320-1325.

5. Wang, X.; Yang, C.; Ju, Z.; Ma, H.; Fu, M. Robot manipulator self-identification for surrounding obstacle detection. Multimed. Tools Appl. 2017, 76, 6495-6520. [CrossRef]

6. Cao, X.; Sun, H.; Jan, G.E. Multi-AUV cooperative target search and tracking in unknown underwater environment. Ocean Eng. 2018, 150, 1-11. [CrossRef]

7. Anderson, B.; Crowell, J. Workhorse AUV-a cost-sensible new autonomous underwater vehicle for surveys/soundings, search \& rescue, and research. In Proceedings of the OCEANS 2005 MTS/IEEE, Washington, DC, USA, 17-23 September 2005; pp. 1-6. 
8. Gibson, S.B.; Stilwell, D.J. Hydrodynamic Parameter Estimation for Autonomous Underwater Vehicles. IEEE J. Ocean. Eng. 2018, 45, 385-394. [CrossRef]

9. Sajedi, Y.; Bozorg, M. Robust estimation of hydrodynamic coefficients of an AUV using Kalman and Ho filters. Ocean Eng. 2019, 182, 386-394. [CrossRef]

10. de Barros, E.A.; Dantas, J.L.; Pascoal, A.M.; de Sá, E. Investigation of normal force and moment coefficients for an AUV at nonlinear angle of attack and sideslip range. IEEE J. Ocean. Eng. 2008, 33, 538-549. [CrossRef]

11. Sabet, M.T.; Daniali, H.M.; Fathi, A.; Alizadeh, E. Identification of an autonomous underwater vehicle hydrodynamic model using the extended, cubature, and transformed unscented Kalman filter. IEEE J. Ocean. Eng. 2017, 43, 457-467. [CrossRef]

12. Allotta, B.; Costanzi, R.; Pugi, L.; Ridolfi, A. Identification of the main hydrodynamic parameters of Typhoon AUV from a reduced experimental dataset. Ocean Eng. 2018, 147, 77-88. [CrossRef]

13. Jagadeesh, P.; Murali, K.; Idichandy, V. Experimental investigation of hydrodynamic force coefficients over AUV hull form. Ocean Eng. 2009, 36, 113-118. [CrossRef]

14. Battista, T.; Woolsey, C.; Perez, T.; Valentinis, F. A dynamic model for underwater vehicle maneuvering near a free surface. IFAC-PapersOnLine 2016, 49, 68-73. [CrossRef]

15. Saeidinezhad, A.; Dehghan, A.; Manshadi, M.D. Experimental investigation of hydrodynamic characteristics of a submersible vehicle model with a non-axisymmetric nose in pitch maneuver. Ocean Eng. 2015, 100, 26-34. [CrossRef]

16. Hai, H.; Zexing, Z.; Jiyong, L.; Qirong, T.; Wanli, Z.; Wang, G. Investigation on the mechanical design and manipulation hydrodynamics for a small sized, single body and streamlined I-AUV. Ocean Eng. 2019, 186, 106106. [CrossRef]

17. Julca Avila, J.; Nishimoto, K.; Mueller Sampaio, C.; Adamowski, J.C. Experimental investigation of the hydrodynamic coefficients of a remotely operated vehicle using a planar motion mechanism. J. Offshore Mech. Arct. Eng. 2012, 134, 021601. [CrossRef]

18. Nouri, N.M.; Mostafapour, K.; Bahadori, R. An apparatus to estimate the hydrodynamic coefficients of autonomous underwater vehicles using water tunnel testing. Rev. Entific Instrum. 2016, 87, 191-233. [CrossRef]

19. Kepler, M.E.; Pawar, S.; Stilwell, D.J.; Brizzolara, S.; Neu, W.L. Assessment of AUV Hydrodynamic Coefficients from Analytic and Semi-Empirical Methods. In Proceedings of the OCEANS 2018 MTS/IEEE, Charleston, SC, USA, 22-25 October 2018; pp. 1-9.

20. Cardenas, P.; de Barros, E.A. Estimation of AUV Hydrodynamic Coefficients Using Analytical and System Identification Approaches. IEEE J. Ocean. Eng. 2020, 45, 1157-1176. [CrossRef]

21. Mansoorzadeh, S.; Javanmard, E. An investigation of free surface effects on drag and lift coefficients of an autonomous underwater vehicle (AUV) using computational and experimental fluid dynamics methods. J. Fluids Struct. 2014, 51, 161-171. [CrossRef]

22. Phillips, A.; Furlong, M.; Turnock, S.R. The use of Computational Fluid Dynamics to Determine the Dynamic Stability of an Autonomous Underwater Vehicle. 2007. Available online: https://eprints.soton.ac.uk/48786/1/ABP_NUTTS.pdf (accessed on 1 February 2021).

23. Singh, Y.; Bhattacharyya, S.K.; Idichandy, V.G. CFD approach to steady state analysis of an underwater glider. In Proceedings of the 2014 Oceans, St. John's, NL, Canada, 14-19 September 2014; pp. 1-5. [CrossRef]

24. Singh, Y.; Bhattacharyya, S.; Idichandy, V. CFD approach to modelling, hydrodynamic analysis and motion characteristics of a laboratory underwater glider with experimental results. J. Ocean Eng. Sci. 2017, 2, 90-119. [CrossRef]

25. Gao, T.; Wang, Y.; Pang, Y.; Chen, Q.; Tang, Y. A time-efficient CFD approach for hydrodynamic coefficient determination and model simplification of submarine. Ocean Eng. 2018, 154, 16-26. [CrossRef]

26. Safari, H.; Abbaspour, M.; Darbandi, M. Numerical study to evaluate the important parameters affecting the hydrodynamic performance of manta ray's in flapping motion. Appl. Ocean Res. 2021, 109, 102559. [CrossRef]

27. Castillo-Zamora, J.J.; Camarillo-Gómez, K.A.; Pérez-Soto, G.I.; Rodríguez-Reséndiz, J.; Morales-Hernández, L.A. Mini-AUV Hydrodynamic Parameters Identification via CFD Simulations and Their Application on Control Performance Evaluation. Sensors 2021, 21, 820. [CrossRef]

28. Deng, F.; Levi, C.; Yin, H.; Duan, M. Identification of an Autonomous Underwater Vehicle hydrodynamic model using three Kalman filters. Ocean Eng. 2021, 229, 108962. [CrossRef]

29. Panda, J.P.; Mitra, A.; Warrior, H.V. A review on the hydrodynamic characteristics of autonomous underwater vehicles. Proc. Inst. Mech. Eng. Part M J. Eng. Marit. Environ. 2021, 235, 15-29.

30. Shariati, S.K.; Mousavizadegan, S.H. The effect of appendages on the hydrodynamic characteristics of an underwater vehicle near the free surface. Appl. Ocean Res. 2017, 67, 31-43. [CrossRef]

31. Tian, W.; Song, B.; Ding, H. Numerical research on the influence of surface waves on the hydrodynamic performance of an AUV. Ocean Eng. 2019, 183, 40-56. [CrossRef]

32. Gabl, R.; Davey, T.; Cao, Y.; Li, Q.; Li, B.; Walker, K.L.; Giorgio-Serchi, F.; Aracri, S.; Kiprakis, A.; Stokes, A.A.; et al. Hydrodynamic loads on a restrained ROV under waves and current. Ocean Eng. 2021, 234, 109279. [CrossRef]

33. Kim, J.; Kim, K.; Choi, H.; Seong, W.; Lee, K.Y. Estimation of hydrodynamic coefficients for an AUV using nonlinear observers. IEEE J. Ocean. Eng. 2002, 27, 830-840. [CrossRef]

34. Tamura, K. Study on the blockage correction. J. Soc. Nav. Archit. Jpn. 1972, 1972, 17-28. [CrossRef]

35. Dias, F.; Dyachenko, A.I.; Zakharov, V.E. Theory of weakly damped free-surface flows: A new formulation based on potential flow solutions. Phys. Lett. A 2008, 372, 1297-1302. [CrossRef]

36. Hashimoto, H.; Yoneda, S.; Omura, T.; Umeda, N.; Matsuda, A.; Stern, F.; Tahara, Y. CFD prediction of wave-induced forces on ships running in irregular stern quartering seas. Ocean Eng. 2019, 188, 106277. [CrossRef] 
37. Soares, C.G. Representation of double-peaked sea wave spectra. Ocean Eng. 1984, 11, 185-207. [CrossRef]

38. Liu, H.L.; Huang, T.T. Summary of DARPA SUBOFF Experimental Program Data; Technical Report; Naval Surface Warfare Center Carderock Div Bethesda Md Hydromechanics: Bethesda, MD, USA, 1998.

39. Garcia de la Torre, J.; Carrasco, B. Hydrodynamic properties of rigid macromolecules composed of ellipsoidal and cylindrical subunits. Biopolym. Orig. Res. Biomol. 2002, 63, 163-167. [CrossRef] [PubMed]

40. Willy, C.J. Attitude Control of an Underwater Vehicle Subjected to Waves. Ph.D. Thesis, Massachusetts Institute of Technology, Cambridge, MA, USA, 1994. 